\title{
EL PROGRESO DE LA EPIGRAFÍA ROMANA EN HISPANIA (1983-1987)*
}

\begin{abstract}
Among the literature produced throughout these last five years, it deserves special interest: the edition of the lex Irnitana and the comments suscited by this outstanding document and by the so-called tahula Siarensis (de honoribus Germanici Caesaris). The most important of the recent discoveries are: the deditio from the Puente de Alcántara (Lusitania), dated in 104 b.C., and five new tabulae patronatus. There must be also cited among the new corpora: Inscriptions romaines de Catalogne (IRC), Inscriçoes do conventus Pacensis and the Epigrafia Romana de Italica.
\end{abstract}

Es ya un hecho llamativo que, de las 321 páginas de que consta el volumen de $A E$ correspondiente a 1986, cien estén dedicadas al apartado Provinces Hispaniques. Si bien es verdad que la "reina» de la epigrafia de estos últimos años la Lex Irnitana ${ }^{1}$ ocupa una buena parte de este espacio, no es menos cierto que la proporción de epígrafes procedentes de suelo hispánico es muy alta: del total de 736 números registrados, casi $200 \quad$ los nn. 273 al 466 corresponden a las provincias hispanas, mientras que Italia tiene sólo 160.

Llamo la atención sobre este hecho porque es representativo de la abundancia de hallazgos y de la creciente atención que en nuestro país se está prestando a los documentos epigráficos. No es ajeno a este inte-

* Incluyo las publicaciones correspondientes al periodo enunciado, disponibles hasta diciembre de 1989. Quiero rendir aquí homenaje de admiración y agradecimiento a los estudiosos de nuestras materias fallecidos en esta etapa: M. Lourdes Albertos, a quien debemos una importante aportación en el campo de la onomástica prerromana; a Sebastián Mariner, ilustre filólogo, autor de una monografia de inscripciones métricas y editor de las inscripciones de Barcelona; al arqueólogo Alberto Balil, corresponsal español de Archäologische Bibliographie, y por último al inolvidable Sir Ronald Syme, que tuvo a Hispania, y especialmente a la Bética, como uno de sus temas de estudio más queridos.

$1 A E 1986$, n. 333 que ocupa las pp. 87-141; además del texto, que sigue la versión de J. González, JRS (infra, n. 39), los editores de $A E$ ofrecen una traducción francesa. 
rés el proyecto de reedición del CIL II, cuya frase primera - recogida del material - se ha cerrado en este quinquenio ${ }^{2}$.

La proliferación de hallazgos, unida a la dispersión de las publicaciones, hacen ardua la tarea de redactar esta crónica, cuya pretensión de exhaustividad se hace prácticamente inalcanzable. Ciñéndome en lo posible a la línea que he venido manteniendo en crónicas anteriores, he distribuido el material en la forma siguiente:

I. Estudios Y NOTICIAS, TEMÁticAMENTE AGRUPAdOS

1. Publicaciones periódicas y crónicas.

2. Estudios de carácter general, misceláneas y actas.

3. Colecciones epigráficas.

4. Época republicana.

5. Leyes y otros documentos de carácter jurídico.

6. Organización ciudadana.

7. Senatores.

8. Equites.

9. Ejército.

10. Flamines y pontifices.

11. Epigrafia pre-romana: cultos y onomástica indígenas.

12. Vías y miliarios.

13. Economía y comercio: marcas de ánforas; instrumenta varia.

14. Inscripciones cristianas y de época visigoda.

II. INSCRIPCIONES AGRUPADAS GEOGRÁFICAMENTE

1. Lusitania.

2. Bética.

3. Tarraconense.

\section{ESTUdios Y NOTICIAS, TEMÁTICAMENTE AGRUPADOS}

\section{Publicaciones periódicas y crónicas}

En 1983 apareció el primer número de la revista Gerión, publicada por el Departamento de Historia Antigua de la Universidad Complutense. La Universidad de Murcia ha iniciado en 1985 una serie de Anales de Prehistoria y Arqueologia; la del País Vasco, la revista Veleia;

2 Acerca de la marcha de esta empresa pueden verse las informaciones del coordinador del proyecto, A. U. Stylow, en Épigraphie Hispanique (Actas de la Table Ronde, Burdeos, diciembre 1981), Burdeos 1984; cf. rec. de G. Alföldy, Germania 63, 2,1985 , pp. 578-581. Otra referencia más reciente de Stylow a esta cuestión, en Epigrafia Juridica Romana (infra, n. 19), p. 30. 
Anales es el título del Anuario que publica desde 1984 el Centro de la UNED en Barbastro. La revista Museos es una serie, nacida en 1982 , que continúa las antiguas Memorias de los Museos Arqueológicos; a iniciativa de diversos museos se deben: el Boletín del Museo Arqueológico Nacional a partir de 1983; el Boletín del Museo de Zaragoza; el Boletín del Museu Provincial de Lugo; Carpetania, lanzada en 1987 por el Museo de Santa Cruz de Toledo; Laietania, dependiente del Museo comarcal del Maresme (Mataró); Numantia, publicada por la Asociación de Amigos del Museo Numantino, y Trabajos de Arqueología Navarra, editado por la Institución Príncipe de Viana (Pamplona). Otras publicaciones nuevas son: Bolskan (Revista de Arqueología Oscense); Oretum (Ciudad Real), y Vettonia (Cáceres). En Portugal: Cadernos de Arqueología inició la 2. a serie en 1984; Lucerna (Porto), nueva serie de Portugalia, y Treharuna (Castelo Branco). Los Cuadernos de Trabajo de la Escuela Española de Historia y Arqueología en Roma empiezan una nueva andadura con el título de Italica.

Son muy escasas las noticias de Hispania recogidas en la reseña que periódicamente publica el JRS bajo el título Roman Inscriptions ${ }^{3}$ : figuran alli la deditio del Puente de Alcántara, la Tabula Contrebiensis, de la que se han ocupado estudiosos anglosajones, y la Tabula Siarensis; a estos documentos nos referiremos en los apartados correspondientes. La crónica de Epigrafia Jurídica Griega y Romana, redactada por A. Magioncalda, constituye un volumen suplementario de $S D H I^{4}$; la parte correspondiente a Hispania abarca las páginas 208-225; esta serie ha quedado interrumpida; en su lugar, $S D H I$ publica ahora artículos misceláneos en los que se comentan novedades sobresalientes ${ }^{5}$. Carácter misceláneo tienen igualmente las ponencias de tema epigráfico presentadas al VI Congreso Español de Estudios Clásicos ${ }^{6}$. M. Mayer e I. Rodá publican informes referidos a las regiones catalana y valenciana en los últimos años ${ }^{7}$.

${ }^{3}$ J. Reynolds, M. Beard y Ch. Rouché, «Roman Inscriptions 1981-1985», JRS 76, 1986, pp. 124-146.

4 A. Magioncalda, "Epigrafia Giuridica Greca e Romana XIII, 1978-1981", SDHI 51, Suppl. 1985, 359 pp.: continúa las elaboradas anteriormente en colaboración con Amelotti, que asumió esta tarea realizada antes durante años por Á. d'Ors.

5 Este carácter tiene la "Miscelánea epigráfica Hispano-Romana», SDHI 52, 1986, pp. 353-394, que contiene noticias, revisión de lecturas y observacionnes críticas distribuidas en 8 apartados.

6 Actas.... Madrid 1983: S. Mariner, Epigrafia Latina, comentarios a una selección de epigrafes, pp. 65-104; C. Castillo, Un trienio de epigrafia latina en Hispania: logros y perspectivas, pp. 105-125.

7 I. Roda, "Estado actual de la epigrafía en Cataluña", Épigraphie Hispanique (supra, n. 2), balance a partir de 1975; M. Mayer-I. Roda, «L'epigrafia romana a 
Disponemos ahora de unos Índices de las Inscripciones Latinas publicadas en el BRAH desde sus comienzos a 1950, útil instrumento de trabajo ${ }^{\text {. }}$.

\section{Estudios de carácter general, misceláneas y actas}

R. Wiegels ha editado un catálogo de las tribus documentadas en Hispania, que pone al día la obra de Kubitscheck en lo referente a la Península ${ }^{9}$; aunque deja algunas cuestiones sin respuesta, su manejo es imprescindible en tanto no aparezca la magna obra en la que trabaja Forni desde hace años. La lista está distribuida por provincias y - dentro de éstas - por orden alfabético de ciudades.

Varios trabajos de Curchin, realizados principalmente con método prosopográfico, se orientan hacia el estudio de la sociedad en la España Romana ${ }^{10}$.

La ponencia presentada por R. Knapp al VIII Congreso Internacional de Epigrafia Griega y Latina, celebrado en Atenas", que tuvo

Catalunya, estat de la questió i darreres troballes", Fonaments 6, 1985, pp. 193-211, y "L'epigrafia romana al pais Valenciá (1982-1986)", Fonaments 7, 1988, pp. 196218.

M. D. Mauleón, Índices de las inscripciones latinas publicadas en el BRAH (1877-1950), Pamplona 1983; rec. M. J. López de Ayala, emfrita 54, 1986, p. 360.

R. Wiegels, Die Tribusinschriften der röm. Spanien. Ein Katalog, Berlín 1985 ( $A E$ 1985, n. 495). Rec.: M. Mayer, Fonaments 6, 1986, pp. 215-218; N. Mackie. JRS 78, 1988, p. 269; J. Gascou, Latomus 48, 1, 1989, pp. 228-229.

Otros estudios onomásticos: J. M. Abascal, Lucentum 3, 1984, pp. 219-259, sobre los cognomina que indican parentesco; S. L. Dyson, "The distribution of Roman Republican Family Names in the Iberian Peninsula", Anc. Soc. 11-12, 1981-82, pp. 257-299.

10 L. A. Curchin, "Personal Wealth in Roman Spain", Historia 32, 1983, pp. 227-243; Idem, "Social Relations in Central Spain: patrons, freedmen and slaves in the life of a Roman provincial hinterland", Anc. Soc. 18, 1987, pp. 75-89: principalmente sobre inscripciones del CIL II, aunque usa otras publicaciones más recientes, sin agotar la bibliografia; idem, "Familial epithets in the epigraphy of Roman Spain", Mél. Gareau, Ottawa 1982, pp. 179-182 ( $A E$ 1982, n. 451); critica de J. Reynolds en JRS 76, 1986, p. 142, n. 190. Poco interés tiene L. A. Curchin, "Demography and Romanization at Tarraco", AEArq. 60, 1987, pp. 159-171: es un intento de extraer conclusiones a base de un análisis estadístico de 821 inscripciones paganas de Tarraco, sobre el catálogo de Alföldy. Acerca del libro de C. García Merino, Población y poblamiento en Hispania Romana: el conventus cluniensis, vid. la critica de N. Mackie, JRS 73, 1983, pp. 236-237. Tampoco llega a conclusiones importantes el trabajo de E. Marin en Bull. d'Archéologie et d'Histoire dalmate 77, 1984, pp. 81-91 sobre la presencia de población de origen occidental, especialmente hispánico, en Salona; acerca de las relaciones entre Dalmacia e Hispania, vid. M. Mayer, ihid., pp. 63-79. R. Portillo publica bajo el título Incolae, Córdoba 1983, una breve monografía sobre este sector de población.

$"$ R. C. Knapp, "The epigraphic evidence for native and Roman religion in Spain", Actas (infra, n. 16), vol. I. En el vol. II: J. M." Blázquez, "L’élément grec 
como objeto el estudio de los cultos romanos en Hispania, está basada casi exclusivamente en el material de CIL II. Al tema de los cultos de Hispania está también dedicado el volumen $\mathrm{V}$ de Memorias de Historia Antigua, que publica la Universidad de Oviedo ${ }^{12}$. Otros trabajos breves abordan distintos aspectos del culto a Júpiter ${ }^{13}$, el culto mitraico ${ }^{14}$, y la presencia de la mujer como dedicante ${ }^{15}$.

Capitulo aparte merece la mención de homenajes que contienen colaboraciones de carácter epigráfico: a C. Fernández Chicarro (Madrid 1982); a M. Almagro Basch (vol. III, Madrid 1983); a R. Fletcher Valls (Valencia 1984); a Pinho Brandão (Oporto 1984); a L. Mitxelena (Vitoria 1985); a A. Beltrán (Zaragoza 1986); a F. R. Adrados (vol. II, Madrid 1987). Incluimos en los apartados correspondientes las distintas colaboraciones contenidas en ellos.

En 1984 y 1987, respectivamente, han aparecido los dos volúmenes correspondientes a las Actas del VIII Congreso de Epigrafia Griega y Latina al que acabamos de hacer referencia. Del IX Congreso, celebrado en Sofia en 1987, se publicó, contemporáneamente a su celebración, un primer volumen de Actas ${ }^{16}$. Las Actas de la Tahle Ronde tenida en Burdeos bajo el título Épigraphie Hispanique. Problèmes de méthode de

dans les religions orientales de la Péninsule Ibérique». Un repertorio de fuentes epigráficas limitado a la región catalana ofrece M. Planas, Actas CPHA (infra, n. 22), pp. 481-494.

I2 Mem. H." Ant. 5, 1981 (publ. 1983). Incluye entre otros: J. d’Encarnação, «A religião romana não-oficial nas colonias e municipios da Lusitania durante o Alto Imperio" ( $A E$ 1983, n. 463); M. M. Alves, "Consideraciones sobre cultos locales en la Hispania Romana»; J. Alvar, "El culto de Mitra en Hispania»; M. J. Pena, "El culto a Tutela en Hispania»; N. Marín, "Religión no oficial en el conventus Astigitanus"; M. Pastor, "El culto a Silvano iinnovación o sincretismo"; S. Santamaria, "Los lares en el conventus Asturum». S. Montero publica en AEArq. 58, 1985, pp. 89-105 un trabajo sobre "Los libertos y su culto a Silvano en Hispania: Cronologia, localización y extracción social de los dedicantes".

${ }_{13}^{3}$ J. Salas et alii, "Un sincretismo religioso en la Peninsula Ibérica: Júpiter Solutorio-Eaeco", Norha 4, 1983, pp. 243-262; E. Sánchez Salor y J. Salas, "El culto a Júpiter Repulsor en la Península Ibérica, según las inscripciones", Norba 5, 1984, pp. $81-94$ ( $A E 1986$, n. 305).

14 J. Alvar, "Un culto enfrentado con el Cristianismo: Mitra", Rev. Arq. 13, 1981, pp. 32-34; E. Romero y A. M. (jaya, "El culto mitraico en Hispania», ihid., pp. 35-39. En discusión con J. Alvar, AEArq. 56, 1983, pp. 123-130, vid. J. d'Enciarnaçào, "Omissão dos teónimos em iscriçōes votivas", Act. IV C'ol. LCCP (infra, n. 18), pp. 305-310, cf. infira, n. 191.

is A. M. Vázquez. Hoys, "La mujer en la epigrafía religiosa hispano-romana", Cuad. de Preh." y Arq. 9-10, 1982-83, pp. 107-150: Corpus de 147 epigrafes. Ead., "Divinidades celestes en la Hispania Romana", Universidad y Sociedad 3, 1981, pp. 171-200.

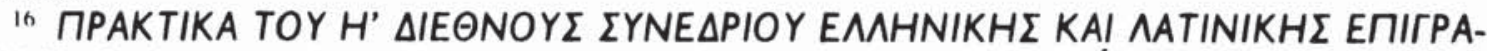

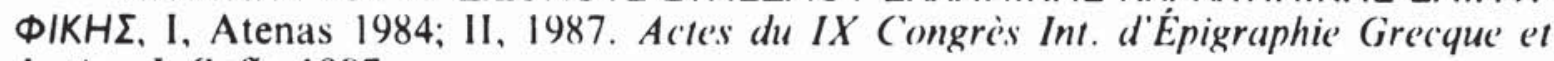
Latine, I, Sofia 1987. 
l'édition, vieron la luz en 1984; su contenido va desde cuestiones relacionadas con la tradición manuscrita hasta el uso de la informática, pasando por comunicaciones que abordan aspectos muy diversos ${ }^{17}$. Las correspondientes al III y IV Coloquio sobre Lengua y Culturas Paleo-hispánicas y al II Congreso sobre Producción y Comercio del aceite en la Antigüedad se han publicado en 1985, 1987 y 1983, respectivamente ${ }^{18}$. Bajo el patrocinio de la A.I.E.G.L. tuvieron lugar en Pamplona, 1987, las sesiones del Coloquio sobre Epigrafia Jurídica Romana, celebrado en homenaje a Á. d'Ors ${ }^{19}$. Otros dos coloquios se han dedicado a cuestiones de carácter jurídico ${ }^{20}$. En 1986 se editaron las Actas de la Reunión sobre Epigrafia Hispánica convocada en Zaragoza ${ }^{21}$. Contienen también estudios de Epigrafia las Actas del Primer Congreso Peninsular de Historia Antigua, y las correspondientes a los Congresos Nacionales de Arqueología, que ocurren con periodicidad bienal ${ }^{22}$.

\section{Colecciones epigráficas}

Continúan apareciendo, con ritmo creciente, catálogos de regiones, provincias, ciudades y museos. Merece la pena destacar la colección Inscriptions Romaines de Catalogne (IRC), editada por G. Fabre, M. Mayer e I. Rodá, bajo el patrocinio conjunto del Instituto de Estudios Catalanes, el Centro Pierre Paris, y la Universidad Autónoma de Bar-

${ }^{17}$ Cf. supra n. 2 ( $A E 1984$, n. 451). Además de la rec. de Alföldy, que citamos más arriba, puede verse Fonaments 6, 1985, pp. 211-213.

18 Actas del III Coloquio sobre Lenguas y Culturas paleohispánicas (Lisboa 1980), Salamanca 1985; Studia paleohispanica. Actas del IV Col. sobre Lenguas y Culturas paleohispánicas (Vitoria 1985), Vitoria 1987 (Veleia 2-3), en adelante LCP; Producción y comercio del aceite en la Antigüedad, II Congr. Int. (Sevilla 1982), Madrid 1983.

${ }_{19}$ Epigrafia Juridica Romana. Actas del Coloquio Int. AIEGL (Pamplona 1987), ed. C. Castillo, Pamplona 1989 (en adelante EJR).

${ }^{20}$ El que tuvo como núcleo central la Tabula Siarensis (Sevilla 1986), Actas, Madrid 1988, vid. infra, n. 54; el titulado Intertiumjagd and the Lex Irnitana, I. A. Crook et alii, ZPE 70, 1987, pp. 173-184 y D. Johnston, JRS 77, 1987, pp. 70-71.

${ }_{21}$ Actas de la Reunión sobre Epigrafia Hispanorromana de époc'a republicana, ed. G. Fatás, Zaragoza 1986 (en adelante EHER). Otras reuniones: Actas del Symposium Vias Romanas del Sureste (Murcia 1986), ed. A. González Blanco, Murcia 1988.

Se encuentran también trabajos epigráficos en: Actas del I Symposium de Arqueologia Soriana, Soria 1984; Actas del I Congreso de Historia de Navarra, vol. 2, Pamplona 1987 (Anejos PV 7).

22 Actas del I Congreso Peninsular de Historia Antigua (Santiago de Compostela 1986), ed. G. Pereira, 3 vols., Santiago de Compostela 1988 (en adelante CPHA); Actas del XVI CNA, Zaragoza 1983; Actas del XVII CNA, Zaragoza 1985; Actas del XVIII CNA, Zaragoza 1987. 
celona ${ }^{23}$. J. d'Encarnação ha publicado un Corpus del Conventus Pacensis, que comprende 680 textos ${ }^{24}$; A. M. ${ }^{\text {a }}$ Canto presenta la epigrafia de Italica, un catálogo de 168 números con sugerentes novedades de lectura e interpretación ${ }^{25}$; parte del material procedente de la provincia de Córdoba ha sido dado a conocer por A. U. Stylow en la serie que aparece en Madrider Mitteilungen bajo el título Beiträge zum lateinischen Epigraphik im Norden der Provinz Cordoba ${ }^{26}$. En Segobriga II reúne M. Almagro las inscripciones ibéricas y latinas de esta ciudad ${ }^{27}$; en la misma serie, P. Palol, las de Clunia ${ }^{28}$; el conjunto de la provincia de Ali-

${ }_{23}$ El proyecto abarca toda la región (abrevio $I R C$ ); van publicados hasta ahora: I, Barcelona (sauf Barcino), París 1984, II, Lerida, París 1985 ( $A E$ 1984, n. 541; 1985. n. 571); rec.: C. Castillo, emfrita 56, 1, 1988, pp. 128-131; Latomus 47, 1988, p. 224; 48,1989 , pp. 227-228; Gerión 4, 1986, pp. 368-370. Quedan integrados en estos volúmenes varios conjuntos menores publicados por los mismos AA.: Arrahona 13, 1982, pp. 35-40 ( $A E 1983$, nn. 611-612); Ausá 10, 1982, pp. 293-318 ( $A E$ 983, nn. 623-625); el de Mataró publicado en 1983 ( $A E$ 1983, n. 542 y nn. 626-630); el de Isona. Act. XVII CNA, Zaragoza 1985, pp. 667-699; Pyrenae 17-18, 1981-82, pp. 667-699 ( $A E$ 1985 , n. 635). Los resultados del trabajo correspondiente a $I R C$ I fueron comunicados al XVI CNA y publicados en Caesaraugusta 63, 1986, pp. 87-102.

De los mismos AA.: "Consideraciones sobre el conjunto epigráfico de Dertosa», Actas XVII CNA, Zaragoza 1985, pp. 701-737; "Inscripciones 'alienae' en museos y colecciones de la provincia de Barcelona", Ampurias 44, 1982, pp. 185-242, con un total de 45. M. Mayer y I. Roda, "Epigrafia romana de la Cerdanya», Hom. Oliva Prat, Puigcerdá 1982, pp. 239-246 ( $A E$ 1984, n. 616), y varios trabajos referentes a epigrafia barcelonesa, vid. supra, n. 16 y también infra, apartado II. 3, con n. 269.

24 J. d'Encarnação, Iscriçóes romanas do Conventus Pacensis, Coimbra 1984 (AE 1984, p. 455; las inéditas en nn. 459-464). Rec.: C. Castillo, emerita 56, 1, 1988, pp. 132-134. Idem, "Epigrafia de Ossonoba (Faro)», Conimbriga 23, 1984, pp. 5-18 (AE 1984, n. 456); en colaboración con R. Carvalho, Belver ao tempo dos Romanos, Portalegre 1984 ( $A E$ 1984, nn. 468-474). Un catálogo de las inscripciones de Idanha a Velha (ciuitas Igaeditanorum) prepara d'Encarnação en colaboración con V. Gil Mantas, cf. CPHA (supra, n. 22), p. 415.

Otros conjuntos menores en Lusitania: V. Gil Mantas, "Museo de Torres Vedras", en Conimbriga 21, 1982, pp. 5-99; J. L. Vaz, Lamego, Lamego 1983.

is A. M." Canto, Epigrafia Romana de Italica, Madrid 1985 ( $A E$ 1985, n. 547) (en adelante ERI). Rec.: A. d'Ors, Iura 36, 1985, pp. 122-123.

26 I, $M M$ 27, 1986, pp. 235-277 (nn. 1-34); II Baedro, MM 28, 1987, pp. 57-97 (nn. 35-69); III Mellaria, MM 28, 1987, pp. 97-125 (nn. 70-84), con un apéndice e indices. Hago referencia a las inéditas y a nuevas lecturas infra, apartado II.2, Bética.

Otros conjuntos de la Bética: M. Pastor y A. Mendoza, Inscripciones latinas de la provincia de Granada, Granada 1987; J. M. Bonneville, S. Dardaine y P. Le Roux, Les inscriptions romaines de Baelo Claudia, Belo V: L'épigraphie, Madrid 1988; J. M. Álvarez Martínez, "Epigrafia reginense», Museos 1, 1982, pp. 9-15.

27 M. Almagro Basch, Segohriga II (Exc. Arq. en España n. 127), Madrid 1984 ( $A E$ 1984, n. 542), cf. infra, nn. 113 y 259. Para las inscripciones de Cuenca: A. Rodriguez. Colmenero, "Cuenca Romana, contribución al estudio epigráfico", Lucentum 1, 1982 ( $A E$ 1982, nn. 600-620) y Lucentum 2, 1983, pp. 319-333 ( $A E$ 1984, nn. 587-597), con lecturas sujetas a revisión, vid. infra, n. 261.

${ }_{2 *}$ P. Palol, Clunia II, La epigrafia (Exc. Arq. en España n. 150), Madrid 1987. con bastantes inéditos. 
cante ha proporcionado 107 textos ${ }^{29}$. Un Corpus seleccionado en función de las características del soporte presentan R. Portillo, P. Rodríguez Oliva y A. U. Stylow ${ }^{30}$.

\section{4. Época republicana}

El gran descubrimiento de estos años ha sido la tabla de bronce encontrada cerca del Puente de Alcántara en la antigua Lusitania, con el texto de una deditio, fechada en el a. 104 a. C. ${ }^{31}$. El texto conservado dice así:

1 C. Mario, C. Flauio [...

L. Caesio C.f. imperatore, populus Seano [...

dedit, L. Caesius L.f. imperator postquam [... accepit ad consilium retolit quid eis in [...

5 censerent de consili sententia imperau [... captiuos equos equas quas cepisent $[\ldots$ omnia dederunt. Deinde eos L. Caesius C.f. [... esse iussit agros et aedificia, leges, cete $[\ldots$ quae sua fuissent pridie quam se dedid [...

10 extarent eis redidit, dum populus $[\ldots$ Romanus uellet deque ea re eos $[\ldots$ eire iussit. Legatos C. Ren [... Arco Cantoni $f$. legates.

Otros conjuntos de la zolia de Castilla la Nueva: J. M. Abascal, «Epigrafia Romana de la provincia de Guadalajara", Wad al Hayara 10, 1983; J. M. Abascal y D. Fernández-Galiano, "Epigrafia Complutense», Museos 3, 1984, pp. 7-36, contiene varias inéditas ( $A E$ 1985, nn. 601-609), con lecturas que deben revisarse; una nueva añade D. Fernández-Galiano, Complutum I (Exc. Arq. en España n. 137), Madrid 1984, con un repertorio de 335 monedas en addenda. S. Cortés et alii, "Nuevas inscripciones romanas del Museo de Santa Cruz de Toledo", Muscos 3, 1984, pp. 73-85 ( $A E$ 1986, nn. 425-434).

29 M. A. Rabanal y J. M. Abascal, "Inscripciones romanas de la provincia de Alicante", Lucentum 4, 1985. pp. 191-244 (AE 1986, nn. 435-443): M. A. Rabanal, Fuentes literarias y epigrạficas de León en la antigüedad, León 1982. F. Diego Santos, Inscripciones romanas de la provincia de León, 1986, con 328 inscripciones (es la tesis de 1972 puesta al día); T. Mañanes, Epigrafia y Numismática de Astorga romana y su entorno, Salamanca 1982 ( $A E$ 1982, nn. 575-576).

Otros conjuntos de la Tarraconense: M." C. González y J. Santos, "La epigrafia del conventus cluniense, I. Las estelas vadinienses", Mem. H." Ant. 6, 1984, pp. 85112, con tres inéditas; J. M. Blázquez et alii, Castulo IV. Madrid 1984, contiene, en anexo, la epigrafia de la ciudad, of. infra, n. 262.

A. Rodriguez Colmenero y M. C. Carreño, "Epigrafia vizcaina», Kohic 11, 1981, pp. 81-164.

31" "Porträthermen mit Inschrift im röm. Hispanien», $M M$ 26, 1985, pp. 185-217 ( $A E$ 1985, nn. 548, 549, 553, 556 y 559).

$"$ R. López Melero et alii, "El bronce de Alcántara, una "deditio" del a. 1(14 a. C.", Gerión 2, 1984, pp. 265-323. 
La restitución de las letras que faltan a la derecha, según la opinión de los editores aproximadamente 5 , ha sido objeto de diversas propuestas ${ }^{32}$. Independientemente de esta dificultad, el interés histórico del hallazgo, primera deditio documentada epigráficamente, es innegable.

La interpretación del iudicium Contrebiense es cuestión controvertida: de una parte Fuenteseca, e independientemente un grupo de estudiosos anglosajones, proponen que se entienda una fictio ciuitatis como solución para explicar la expresión sei Sosinestana ceiuitas esset; a mi modo de ver, puede explicarse el subjuntivo sin necesidad de recurrir a esa interpretación forzada, simplemente atendiendo a la estructura formularia del texto: sei Sosinestana ciuitas esset debe referirse a una supuesta resolución positiva de la primera fase: sei parret, iure suo iudic'ent. Dicho de otro modo: sólo en el caso de que los jueces decidan que los Sosinestanos tienen rango de ciuitas (derecho a enajenar terrenos), se plantea la segunda cuestión: es decir, si el terreno vendido pertenecía al ager publicus o al ager priuatus, y si era lícita la construcción de una empalizada. La tercera fase -... sei iudicarent riuom facere licere sólo entra en juego si se resuelve positivamente la segunda. Son estas fórmulas de enjuiciamiento, con sus tres fases, las que aprueba el gobernador romano con la addictio ${ }^{33}$.

El texto de Italica (CIL I $\mathrm{I}^{2} 546$, II 1119), que recuerda la donación hecha por un imperator, y que tradicionalmente se venía atribuyendo al cónsul Mumio, conquistador de Corinto, ha sido objeto de una restitución por parte de A. M. ${ }^{\text {a }}$ Canto, que propone en lugar de Mumio a L.

32 En $A E 1984$, n. 495 se indica la insuficiencia de los complementos propuestos por los editores, y la dificultad de interpretar ( $R E N$ (lín. 12), que he separado según mi lectura, vid. SDHI 52, 1986, pp. 353-361; otra restitución propone J. S. Richardson, en su libro sobre las Hispaniae bajo la República, Cambridge 1986, p. 199 s.; en $A E$ 1986, n. 304 se recoge el texto según Richardson y complementariamente. el mio. Otras lecturas proponen L. Garcia Moreno, EJR (supra, n. 19), pp. 244-245 y S. Mariner, ibid.. p. 265; una monografia sobre este documento prepara D. Nörr. Sobre la formula populus senatusque Romamus, F. Martin, (ierión 4, 1986, pp. 313317.

"Vid. "Observaciones sobre el bronce de Contrebia", SI)HI 52, 1986, pp. 36I366. con la bibliografia hasta entonces conocida. Los articulos de J. S. Richardson y sus colegas están recogidos en $A E$ 1983, n. 602 y 1984. n. 586; la opinión de $P$. Fuenteseca, en EHER (supra, n. 21), pp. 177-181. ()tros estudios: R. Lázaro, EHER, pp. 137-139; A. Torrent, "FI origen de la 'servitus aquateductus' a la luz de la 'Tabula Contrebiensis'», St. in onore di A. Biscardi II, Milán 1982, pp. 261-279; idem, "El arbitraje en el bronde de Contrebia", St. in onore di ('. San Filippo II. Milán 1982. pp. 637-654; J. J. de los Mozos, "Commento iuridico sul bronzo di Contrebia", BIDR 1982, pp. 283-297; J. L. Murga, "La 'addictio' del gobernador en los litigios provinciales", $R I D A 30,1983$, p. 151 ss. 
Emilio Paulo ${ }^{34}$. A M. Junio Silano, gobernador de la Citerior a. 113112 a. C., se atribuye una lápida hallada en $1983^{35}$.

Un nuevo texto de interés histórico, fechado en el a. 49 a. C., ha sido encontrado en La Rambla (prov. de Córdoba); documenta epigráficamente la acumulación de cargos - tribuno de la plebe y propretor de la Ulterior - extra ordinem, en la persona de Casio Longino; dice así: L. Lentulo, C. Mercello cos./ Q. Cassio C.f. Long(ino) tr. pl. pro pr. / Binsnes (sic) Vercellonis f. Xuir max. / M. Coranus Acrin(i) f. Alpis / aedilis, portam faciund(am) coer(auerunt) $\left[\right.$ d] e sua pecun $(i a)^{36}$.

Hay noticias de nuevos glandes de plomo con la leyenda $Q$. Sertorius pro $\cos ^{37}$. Una inscripción musiva de época tardorrepublicana 0 quizá augustea, documenta a un $M$. Trahius, que pudo ser un antepasado de Trajano ${ }^{38}$.

\section{Leyes y otros textos de carácter juridico}

A la edición del texto de la Lex Irnitana ${ }^{39}$, han seguido, como era

${ }^{34}$ A. M. Canto, Epigraphica 47, 1985, pp. 9-20, EHER (supra, n. 21), pp. $227-$ 238 (AE 1985, n. 551): [L. Aimi]lius L. f. imperator / [ded(it) Za]kinto capta / [ciuit(ati) Ita]licensi; pongo algunos reparos a esta propuesta en comunicación presentada al VII Congr. Esp. de Est. Clás., Madrid 1987 (Actas 1989), pp. 54-56.

Sobre el decreto de la Turris Lascutana, vid. L. García Moreno, EHER, pp. $195-$ 218; F. Marco Simón, ibid., pp. 219-225; F. Martín, ibid., pp. 235-238. Otros estudios en el mismo volumen. J. Arce, "Hispania en la epigrafia republicana de Italia», pp. 103-113; J. M. Roldán, "El bronce de Ascoli en su contexto histórico», pp. 115-135; M. Mayer e I. Rodá, "La epigrafia republicana en Cataluña: su reflejo en la red viaria", pp. 189-191; C. Castillo, "De epigrafia republicana hispano-romana», pp. 141-150.

${ }^{35} \mathrm{~J}$. Aquilve et alii, EHER, pp. 151-156; idem, El forum romá d'Empuries, Barcelona 1984, con algunas inscripciones nuevas, vid. infra, n. 89.

${ }^{36}$ P. J. Lacort, R. Portillo y A. U. Stylow, Faventia 8, 1, 1986, pp. 69-78 (AE 1986, n. 369). Un comentario a este texto hago en $S D H I$ 52, 1986, pp. 376-381.

La inscripción de Zaragoza llamada de la "puerta romana», si es auténtica, debe de corresponder también a época republicana, vid. mi comunicación al VII Congr. Esp. de Est. Clás., Madrid 1987 (Actas 1989), pp. 56-59.

${ }^{37}$ G. Chic, EHER, pp. 171-175: dos encontrados en la provincia de Huelva. Además: A. Dominguez et alii, Carta Arqueológica de Huesc'a, Zaragoza 1984, p. 160, reproducido por F. Beltrán, Anales 4, 1987, p. 25; ibid. se da noticia de otro inédito hallado en los alrededores de Pamplona.

V. Durán y M. Ferrero, Habis 15, 1984, p. 233 ss., publican un pasador de plata con la leyenda $\boldsymbol{A}$. Varo, hallado en el lugar donde se sitúa la batalla de Munda; lo atribuyen a Attius Varus, general pompeyano que perdió allí la vida.

38 J. Gil, Gerión 4, 1986, pp. 325-327 y A. Caballos, Habis 18-19, 1987-88, pp. 299-317: incompleta, con reconstrucción hipotética. Cuatro epigrafes de época republicana sobre pavimentos en Cartagena: S. Ramallo, EHER, pp. 183-187.

39 J. González, "The Lex Irnitana: a new copy of the Flavian Municipal Law», JRS 76, 1986, pp. 147-243: texto latino con comentario; trad. inglesa y dos apéndi- 
de esperar, numerosos estudios ${ }^{40}$. Sobre bases diplomáticas, deduce Mourgues que el documento que figura al final de la copia de Irni es una suscriptio: un rescripto dirigido por Domiciano en respuesta al libellus de una comunidad distinta de la Irnitana; esta redacción que incluía la suscriptio del Emperador, unida al "capítulo extravagante» - rúbrica sobre libertos - debía de figurar en una de las versiones, no exclusiva de Irni, de la Ley Flavia Municipal ${ }^{41}$. Quizá la cuestión de mayor envergadura surgida en torno a la lex es la discusión acerca de si pueden o no verse en ella datos constitutivos de la peculiaridad del ius Latii frente a la ciudadanía romana ${ }^{42}$. Hanard observa que la existencia en Irni (y también en Salpensa) de instituciones como patria potestas, manus, mancipium, etc., está en contradicción con la enseñanza de Gayo, según la cual estos derechos competen en exclusiva a los ciues Romani: concluye que el legislador ha empleado expresiones técnicas estereotipadas, haciendo uso abusivo de ellas ${ }^{43}$. Otro elemento perturbador es la mención de la tribus entre los datos que deben figurar en la publicación de los nombres de los jueces ${ }^{44}$.

ces de M. Crawford; en $A E$ 1986, n. 333, texto latino con trad. francesa; una trad. española había publicado Á. d'Ors, $A H D E, 1984$, pp. 535-573, siguiendo el texto, entonces inédito, según podia reconstruirse a través de fotos; simultáneamente a la edición de JRS apareció esta otra versión: Á. d'Ors, La ley Flavia municipal (texto y comentario), Roma 1986; con posterioridad, este estudioso ha editado de nuevo el texto, teniendo en cuenta las mejoras que proporciona la edición de $J R S$, acompañado de una traducción española: Á. d'Ors y J. d'Ors, Lex Irnitana (texto bilingüe), Santiago de Compostela 1988 (Cuad. Compostelanos de Derecho Romano n. 1).

41) Para los trabajos sobre aspectos parciales publicados con anterioridad a 1986, puede verse $S D H I 52,1986$, pp. 389-394 y $A E 1984$, n. 454.

A propósito de la interpretación de d'Ors sobre Litem suam facere, SDHI 48 , 1982, pp. 368-394, vid. I. Cremades y J. Paricio, $A H D E$ 54, 1984, pp. 179-208 y P. B. H. Birks, Rev. d'Hist. du Droit 52, 1984, pp. 373-387.

Otros estudios: J. L. Murga, "Las acciones populares en el municipio de 'Irni'», BIRD 88, 1985, pp. 209-260; S. Demougin, "La Lex Flavia dans une inscription campanienne", Mém. du Centre Jean Palerne de l'Univ. de St. Étienne 7, 1986, pp. 41-47; D. Johnston, "Three Thoughts on Roman Private Law and the Lex Irnitana", JRS 77, 1987, pp. 62-77; J. A. Crook, D. Johnston y P. G. Stein, Intertiumjagd and the Lex Irnitana: a colloquium, ZPE 70, 1987, pp. 173-184; C. Castillo, EJR (supra, n. 19), pp. 291-295.

${ }_{41}$ J. L. Mourgues, "The so-called letter of Domitian at the end of the 'Lex Irnitana'», JRS 77, 1987, pp. 78-87. H. Galsterer, "Municipium Flavium Irnitanum': a latin town in Spain», JRS 78, 1988, pp. 78-90 opina que la reflexión de Mourgues es excesivamente complicada; promete ocuparse de la cuestión más adelante. Por otro lado, propone una reconstrucción de la estructura de la ley que no coincide con la establecida por d'Ors.

42 Sobre los ciues latini, vid. recientemente G. Alföldy, Bayer-Vorg. Bl. 51, 1986, p. 187 ss. y EJR (supra, n. 19), p. 20; otros estudios sobre el ius Latii, infra, nn. 48, 53 y 66 .

${ }^{43}$ G. Hanard, RIDA 34, 1987, pp. 173-180.

44 Vid. C. Castillo, EJR (supra, n. 19), pp. 293-294; H. Galsterer, Rev. Hist. de 
La coincidencia de un pasaje del texto de la Irnitana con el que se conserva en el llamado "fragmento italicense», ha dado pie a J. González para afirmar que Italica no fue nunca municipio de derecho romano, sino latino, como Irni ${ }^{45}$; en contra de esta opinión se manifiesta A. M. a Canto, que - basándose en testimonios arqueológicos - atribuye este fragmento a Cortegana, identificable con la antigua Corticata, en la provincia de Huelva ${ }^{46}$; J. González, por su parte, niega verosimilitud a esta atribución, apoyándose en la inexistencia de restos romanos en torno a la actual Cortegana ${ }^{47}$.

$\mathrm{Ha}$ aparecido una nueva edición de la lex Malacitana ${ }^{48}$. Varios fragmentos de bronce, que reproducen distintos pasajes de la ley municipal, han sido atribuidos al municipio Basiliponense ${ }^{49}$; otros, correspondientes a los capitulos 62 y 63 de la misma ley Flavia, se atribuyen a Ostippo ${ }^{50}$.

En 1984 se publicó una nueva edición de la Tabula Siarensis, con comentario y traducción española ${ }^{51}$. Los trabajos en torno a este im-

Droit Franşais et Étranger 65, 2, 1987, pp. $187-203$ piensa que esta mención es un préstamo; defiende la opinión de que las leyes municipales que conocemos están compuestas de elementos reunidos "de aqui y de allá», destinadas a una ciudad concreta y adaptando una ley modelo válida para varias colonias o municipios, pero que no debía de haber, como ya escribió Mommsen, una ley general para toda la organización de la vida municipal.

${ }_{45}$ J. González, $M C V$ 20,1984, pp. 17-43. Encaja esta propuesta en la hipótesis. del A., según la cual no existieron municipia romana en provincias, idea que se apoya en la interpretación que hace de Tabula Siarensis II, col. b, lin. 25, vid. infra, n. 53.

th A. M.a Canto, "À propos de la loi municipale de Corticata (Cartagena), Huelva, Espagne», $Z P E$ 63, 1986, pp. 217-220 ( $A E$ 1986, n. 309).

47 J. González, "More on the Italica fragment of 'Lex Municipalis'», ZPE 70, 1987, pp. 217-220.

${ }^{4 \times}$ Th. Spitzl, Lex Municipii Malacitani, Munich 1984: contiene una introducción sobre el ius Latii (aunque no ha incorporado la bibliografia más reciente sobre la cuestión), el texto latino con traducción, y un comentario por capítulos; rec. Á. d’Ors, SDHI 51, 1985, p. 627 ss. y H. Wolff, ZSS 104, 1987, p. 723 ss.

49 J. González, $S D H I$ 49, 1983, pp. 395-399; no obstante, en $A E 1984$, n. 510 se hace notar que la distancia marcada por el Itin. Ant. entre Sevilla y Basilippo no coincide con el lugar de hallazgo de los bronces. El A. anuncia una nueva publicación de estos fragmentos y otros nuevos en JRS 1987 (pero no hay nada de esto alli). Á. d’Ors, emerita 53, 1, 1985, pp. 31-41 propone la integración de estos fragmentos y de otros ya conocidos de la misma tabla en el conjunto de la Ley Flavia Municipal. Sobre el cap. 29 de la Lex Salpensana y su modelo escribe C. Cosentini, St. San Filippo 7, Milán 1987, p. 165 ss.

50 A. Marcos Pous, Corduba Archaeologica 12, 1982-83, pp. 43-63, con un amplio excursus sobre la localización de Ostippo.

51 J. González, ZPE 55, 1984, pp. 55-100; add. et corr. ZPE 60, 1985, p. 146 ( $A E$ 1984 , n. 508), donde se manifiesta discordancia respecto al estatuto juridico que el editor supone para la ciudad donde se han encontrado los bronces; la misma disconformidad pongo de relieve en SDHI 52, 1986, p. 386, n. 105. 
portante documento siguen de una parte la línea de correcciones al texto establecido por J. González --línea en la que destacan los ya numerosos artículos de Lebeck ${ }^{52}$-_; de otra parte, las interpretaciones del contenido, entre las que debe destacarse la discusión sobre la opinión emitida por J. González, que sostiene la inexistencia de municipia romana en provincias, en la época que corresponde a la redacción del epígra$\mathrm{fe}^{53}$. En mayo de 1986 se celebró en Sevilla un Coloquio Internacional sobre este documento ${ }^{54}$.

A las tablas de bronce de Vipasca ha dedicado una monografia Domergue $^{55}$ : el A., que ofrece una revisión del texto con traducción y un amplio comentario, califica estos bronces de "mosaicos jurídicos» cuya cronología establece en la época de Adriano (Vip. II) y finales del s. I o comienzos del II (Vip. I).

La Oratio de pretiis gladiatoriis minuendis contenida en un bronce de

"Los publicados hasta 1987 son: W. D. Lebeck, "Schwierige Stellen der Tabula Siarensis", ZPE 66, 1986, pp. 31-48: propone diferentes suplementos para las linn. 3-8 del fragm. I (parte introductoria) y fragm. II col. a) linn. 6-7; completa las linn. 3-7 del fragm. II col. b) y corrige en esta misma col. las linn. 11-15. Idem, "Die drei Ehrungen für Germanicus", $Z P E$ 67, 1987, pp. 127-148: introduce algunas mejoras en el fragm. I linn. 9-34. Idem, "Kleinere Erganzungsprobleme in der T.S.", Z.PE 70, 1987, pp. 57-62: fragm. I linn. 27-28; fragm. II a) linn. 8-14; critica la redacción latina de linn. 11-14, reproducida sin enmiendas en $A E$. Cl. Nicolet, MEFRA 97, 2. 1985 , p. 824 estudia el pasaje referente a las 35 tribus (cf. $A E 1984$, n. 508). Algunas precisiones a la traducción propone J. Arce, AEArq. 57, 1984, pp. 149-154.

${ }_{53} \mathrm{~J}$. González sostiene esta misma opinión en Hahis 17, 1986, pp. 221-242 y en Athenaeum 65, 1987, p. 317 ss. En desacuerdo con esta tesis, apoyada en su interpretación del fragm. II b) linn. 21-27: J. Gascou, Latomus 45, 1986, pp. 541-554, que propone un error del grabador; de acuerdo con la opinión de Gascou, M. Leglay, E.JR (supra, n. 19), p. 188; otras opiniones en contra de la tesis de González: P. Le Roux, "Municipe et droit latin en Hispanie sous l'Empire", Rev. Hist. de Droit Fran(ais 'l Étranger 64, 1986, pp. 325-350; idem, "Siarum' et la 'Tabula Siarensis': statut politique», Estudios... (infra, n. 54), pp. 21-34; C. Castillo, SDHI 52, 1986, p. 384 ss., donde propongo otra interpretación del pasaje en cuestión, of. EJR, p. 288; H. Galsterer, "The 'Tabula Siarensis' and the Augustan Municipalization in Baetical", EsIudios... (infira, n. 54), pp. 61-71 y A. M." Canto, EJR, p. 297.

${ }^{4}$ Vid. supra, n. 20); Actas: Estudios sobre la 'Tahula Siarensis', Madrid 1988. edd. J. González y J. Arce. Contiene varios trabajos sobre este documento además de otros no directamente relacionados con él; en apéndice, una nueva edición de $J$. González, que no tiene en cuenta los suplementos propuestos por Lebeck.

Otros trabajos sobre la Siarensis: G. Zecchini, "La 'Tabula Siarensis' e la 'dissimulatio" de Tiberio", ZPE 66, 1986, pp. 23-29; D. S. Potter, "Tiberius, the Senate and the Eastern Boundary of the Roman Empire», ZPE 69, 1987, pp. 269-276: F. Martín, EJR, p. 42 ss.

${ }^{5}$ Cl. Domergue, La mine antique d'Aljustrel (Portugal) e't les table's de bronze de Vipasca, París $1983(A E$ 1983, n. 464), donde se subrayan las reflexiones en torno a la occupatio, el estatuto del colonus y el alcance general y local de la Lex de metallis dicta; rec. G. S. Susini, Epigraphica 46, 1984, pp. 210-211; R. Chevalier, Latomus 44. 1985, pp. 708-709. Sobre este documento también: D. Capanelli, BIDR, 1983-84, pp. $121-146$. 
Italica (CIL II 6278) ha sido objeto de un amplio comentario por parte de A. M. ${ }^{a}$ Canto, que atribuye el discurso a un senador italicense ${ }^{56}$. J. González ha dado a conocer un fragmento de epístola de Antonino Pío hallado en la provincia de Sevilla, que proporciona el nombre de un nuevo procónsul de la Bética ${ }^{57}$.

No cesan de aparecer nuevas tesserae hospitales indigenas ${ }^{58}$. Por otro lado, el período que nos ocupa ha sido rico en aportaciones de nuevas tabulae, hospitales y de patronato. Especial interés reviste la hallada en un lugar incierto en la provincia de Lugo o en la de León, cuyo texto dice:

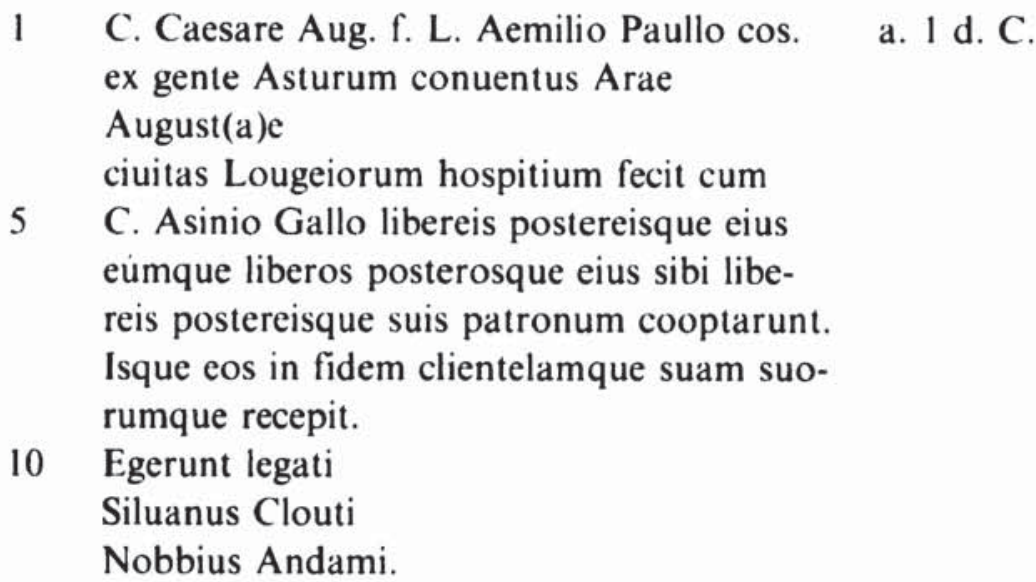

La importancia del patrono, el hijo menor de Asinio Polión, casado con la hija de Agripa que había sido esposa de Tiberio; su relación, hasta ahora desconocida, con la provincia Tarraconense, y la noticia de la existencia de conuentus ya en época de Augusto son puntos que justifican el interés por esta nueva tabula ${ }^{54}$.

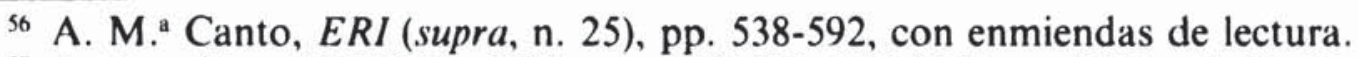

57 J. González, $S D H I$ 49, 1983, pp. 400-403 ( $A E$ 1984, n. 511); cf. C. Castillo, $E J R$, p. 296 s. y F. Martín, ibid., p. 38 s.

Otro epígrafe, publicado también por J. González, contiene la autorización de Antonino Pío para la constitución de un collegium centonariorum en Hispalis, vid. infra, n. 72.

58 A Tovar, Emerita 51, 1, 1983, pp. 2-3: una pequeña, en forma de jabalí, con caracteres ibéricos, procedente de la prov. de Cuenca, da el nombre de una nueva gentilidad, que se transcribe Atulicum; en esta misma provincia, M. Almagro Basch, "Tres téseras celtibéricas de bronce de la región de Segóbriga", Hom. C. Fernández Chicarro, Madrid 1982, pp. 195-206. Otra nueva en la región de Vxama: C. Garcia Merino y M.a L. Albertos, Actas III Col. LCP (supra, n. 18), pp. 311-317; en Aragón: G. Fatás, "Una tésera cortenense», Symbolae I (Hom. Mitxelena), pp. 425-431. Sobre este tipo de documentos, vid. SDHI 52, 1986, pp. 366-369.

${ }^{59}$ G. Pereira Menaut, Veleia 1, 1984, p. 282, cf. AE 1984, n. 553; idem, Actas IV Col. LCP (supra, n. 18), pp. 299-304; idem, Actas del II Congr. Gallego de Est. Clás., Santiago de Compostela; vid. M. ${ }^{\text {a }}$ D. Dopico, "Los 'conventus iuridici'. Origen, cro-
} 
En Monte Murado se han encontrado otras dos tabulae, con datación consular de los a. 7 y 9 d. C. ${ }^{60}$; una tabla de bronce opistógrafa, procedente de la Bética, contiene: a) un pacto de hospitalidad entre la ciudad de Baxo y la Colonia Claritas Iulia, fechado en el a. 31 d. C.; b) un patronato gremial del a. $247^{61}$. Un nuevo bronce, fechado el 3 de octubre del a. $134^{62}$, cuya interpretación está siendo ampliamente discutida, contiene la renovación de un pacto en los siguientes términos:

1 L. Iulio Vrso Seruiano III, Publio Viuio (sic) Varo cos. V Non. Octobres [G]ranius Silo et Aemilius Sapienus et Iulius Proculus tesseram hospita-

5 lem pro meritis Elaesi Ottae Aii filii nomine cognationis Magilancum Amallobrigenses Cab[u?]rumuria et Paligo renouarunt cum senatu populoque Caucen-

10 sium in perpetuum sibi liberis posterisque omnibus eorum per legatos M. Valerium Lentulum Iluirum et Lucium Sempronium Quadratum.

La escasa documentación sobre itinera priuata se ha visto aumentada por un nuevo hallazgo ${ }^{63}$.

nología y naturaleza histórica", Gerión 4, 1986, pp. 265-283. Además: J. Enriquez. "Una nueva 'tabula patronatus"», EJR (supra, n. 19), pp. 289-306, con la discusión que sigue, y C. Castillo, ibid., pp. 279-280. Sobre hospitium y patronatus, vid. J. Mangas, Dialogues d'hist. Rom. 9, 1983, pp. 165-184.

(6) A. Coelho Ferreira da Silva, Gaia 1, 1983, pp. 1-26, cf. $A E$ 1983, nn. 476-477; vid. SDHI 52, 1986, pp. 371-373.

6) J. F. Rodríguez Neila y J. M. Santero, Hahis 13, 1982, pp. 105-163 ( $A E 1983$. n. 53()); una versión mejorada del segundo texto: A. U. Stylow, Gerión 3, 1985, pp. 326-331 ( $A E$ 1985, n. 564); vid. C. Castillo, SDHI 52, 1986, p. 373 s. y EJR pp. 281283.

Sobre el patronato de ciudades, vid. J. N. Bonneville, "Les patrons du municipe d'Emporiae (Ampurias)", REA 88, 1986, pp. 181-200; R. Duthoy, "Le profil social des patrons municipaux en Italie sous le Haut Empire", Anc. Soc. 15-17, 1984-86, pp. 121-153; J. U. Krause, "Das Spätantike Städtepatronat», Chiron 17, 1987, pp. 180 .

6. G. Bravo, Gerión 3, 1985, pp. 309-315, cf. AE 1985, n. 581; idem, EJR (supra, n. 19), pp. 307-320 con la discusión que sigue. La noticia en A. Balil, Epigraphica 49. 1987, pp. 266-267; este A., en colaboración con otros, ha preparado una monografia aparecida en 1988. De ello se ha ocupado además A. Montenegro, Hisp. Ant. 11-12, 1981-1985, pp. 105-118 y Actas Congr. Hist. de Palencia I 1, pp. 517-519.

${ }^{63}$ F. Beltrán y F. Arasa, Hisp. Ant. 9-10, 1979-1980 (publ. 1983), pp. 9-10: Iter priuatum / M. Baebi Se- / uerini.

F. Marco Simón, CPHA (cf. supra, n. 22) III, pp. 19-22: un bronce con la inscripción $u e[n]$ alis non est, sin paralelos conocidos. 


\section{Organización ciudadana}

N. Mackie ha publicado una monografia en la que, sobre bases fundamentalmente epigráficas, presenta un panorama de la administración local en Hispania entre la muerte de Augusto y el a. $212^{64}$. A propósito de $C I L$ II 3423,3424 y 5941 , J. le Gall aborda el problema de las ciudadanias múltiples ${ }^{65}$. Dentro de la actual discusión acerca de la naturaleza jurídica del ius Latii en época imperial, de la que es exponente un trabajo reciente de Humbert, puede encuadrarse toda la bibliografia suscitada por la interpretación de la Tabula Siarensis, que queda reseñada más arriba ${ }^{\text {to; }}$ A. U. Stylow ha presentado, reunidos y revisados, cuatro textos directamente relacionados con la concesión de Vespasiano, que presentan la fórmula c(iuitatem) $R$ (omanam) per honorem consecutus, entre los a. 75 y $84^{67}$.

Fruto del trabajo de elaboración sistemática del material correspondiente a las actuales provincias de Cuenca, Guadalajara, Ciudad Real y Toledo, con vistas a la nueva edición del $C I L I I$, es una monografía de Alföldy que abarca este ámbito ${ }^{68}$. Hay ciudades importantes como Corduba, Emerita, Tarraco, Barcino y Emporiae, sobre las que ha recaido la atención de diferentes estudiosos ${ }^{69}$; de otras, se ha elaborado un status

${ }^{\circ 4}$ N. Mackie, Local Administration in Roman Spain a. D. 14-212, Oxford 1983 (British Archaeological Reports, Internat. ser. 172).

Otros estudios referidos a la organización ciudadana: M." J. Pena, "Apuntes y observaciones sobre las primeras fundaciones romanas en Hispania", Est. de la Antigüedad 1, 1984, p. 60 ss.; M. A. Marín, "Las ciudades federadas de 'Hispania' en la "NH' de Plinio", CPHA (supra, n. 22), pp. 409-414; L. A. Curchin, "Vici" and 'pagi" in Roman Spain", REA 87, 1985, pp. 327-343; J. F. Rodriguez. Neila, "Estructura municipal de las comunidades béticas en el marco administrativo de la Hispania Romana, 1. Los órganos de gobierno", Axerquia 10, 1984, pp. 131-153; A. Tranoy, "Remarques sur la permanence et les mutations dans la Galice antique: le rôle des villes", Act. II Sem. de Arq. del N-O. Madrid 1983, pp. 195-201; M. Mayer e I. Rodá, "La estructura municipal en la costa oriental de la Hispania Citcrior", EJR (supra, n. 19), pp. 77-87.

65 J. Le Gall, Hom. Almagro III, 1983, pp. 339-345 (AE 1986, n. 546). Para lo referente a las tribus, vid. supra, n. 9.

th M. Humbert, "Le droit latin impérial: cités latines ou citoyenneté latine?, Ktema 6, 1981, pp. 207-226. Vid. la bibliografia citada supra, nn. 45 y 53.

${ }_{67}$ A. U. Stylow, Gerion 4, 1986, pp. 290-303 ( $A E$ 1986, n. 334).

${ }^{\text {t* }} \mathrm{G}$. Alföldy, Römisches Städte'we'sen auf der Neukastilischen Hoche'hene, Heidelberg 1987; vid. infra, apartado II. 3: Tarraconensis.

h' Corduba: A. Ibáñez. Castro, Córdoba hispanorromana, Córdoba 1983; R. C. Knapp, Roman Corduba, Berkeley 1983, con un indice de fuentes epigráficas. Rec.: Latomus 45, 1986, p. 221; Athenaeum 63, 1985, p. 544 s. Emerita: Acerca del nombre, R. Étienne y F. Mayet, Hom. a Pinho Brandão, Lucerna, s.n., Porto 1984, pp. 159-172 ( $A E$ 1984, nn. 490-492); J. Álvarez Sáenz de Buruaga, Museos 1, 1982, pp. 5-7 ( $A E$ 1986, n. 306); sobre la fundación: A. M. Canto, Act. Col. Römische Städte' 
quaestionis, o bien se ha redactado la historia ${ }^{70}$; varios estudios abordan el tema de la localización de diversas ciudades romanas ${ }^{71}$; uno de ellos, en el que se da a conocer una dedicatoria puesta a Trajano en el a. 114 - asegura la existencia de una ciudad llamada Saepo (conu. Hispalensis) distinta de Vsaepo (Conu. Gaditanus) ${ }^{72}$. Tenemos la primera mención epigrafia de Ipolcubulcula como municipio, y también la primera de Capera como municipio Flavio ${ }^{73}$.

in Spanien, ed. P. Zanker, cit. en $M M$ 26, 1985, p. 137 ss. donde también trata de la situación de esta ciudad.

Tarraco y Barcino: R. Syme, "Rival cities, notably Tarraco and Barcino», Ktema 6. 1981, pp. 271-285, con interesantes referencias a los senadores originarios de estas ciudades; G. Alföldy, "Elites municipales de Tarraco, Barcino y Saguntum», Gerión 2. 1984, pp. 193-238.

Emporiae: sobre la fundación, L. Moretti, «Eroi greci fondatori di Alicante e di Ampurias", RFSClas. 112, 1984, pp. 63-70; sobre el estatuto juridico, M." J. Pena, CPHA (supra, n. 22), pp. 455-466; sobre el patronato de Domicio Calvino, E. Ripoll, Hom. Almagro III, Madrid 1983, pp. 278-285.

${ }^{70}$ A. Beltrán, "Cartagena en la antigüedad. Estado de la cuestión», $A c t$. XVI C'NA, Zaragoza 1983; M. Beltrán, Los origenes de Zaragoza y la época de Augusto. Estado de los conocimientos, Zaragoza 1983; idem, Celsa, la primera colonia romana e'n el valle del Ehro, Zaragoza 1983; U. Espinosa, Calagurris Iulia, Logroño 1984, rec. Athenaeum 64, 1986, pp. 260-261; M." L. Albertos, "Lo que sabemos de las ciudades antiguas de Álava", Veleia I, 1984, pp. 267-270; A. Fuentes, "Valeria", una ciudad olvidada en los textos clásicos", Re'v. de' Arq. 22, 1982, pp. 44-53; G. Pereira, "Valentini veterani et veteres", $A P L .17,1987$, pp. 337-340; F. Arasa, "Consideraciones en torno a la 'republica Leserensis'", Saguntum 20, 1986, pp. 165-241; M. Mayer e I. Roda, "Consideraciones sobre el topónimo 'Pollentia' y el asentamiento romano en la bahía de Pollensa", Act. Symp. de Arq. "Pollentia" y la romanización de las Balcures, 1983, pp. 25-34; M. P. González Conde, "Promoción juridica y organización municipal de 'Complutum' en el Alto Imperio", Lucentum 4, 1985, pp. 133-146; J. M. Serrano, "Colonia Augusta Gemella Tucci», Habis 12, 1981 (publ. 198.3) pp. 203222 (cf. idem, Actas del III Congr. Andaluz de Est. Clás., Jaén 1981, pp. 435-440) y AE 1985, n. 554); A. Caballos, "Iptuci", civitas stipendiaria del conventus Gaditanus", Gades 7, 1981, pp. 37-46; J. J. Sayas, “Norba Caesarina' y sus contributa 'Castra Servilia' y 'Castra Caecilia'», $M\left({ }^{\prime} V 21,1985\right.$, pp. 61-75.

71 J. González, "Las monedas con la leyeda 'IL. SE' y el emplazamiento de 'Segida Restituta Iulia'", Numisma 177-179, 1982, pp. 45-51: Segıda no es Zafra, sino las ruinas del Cerro del Castillo (Sevilla) a $13 \mathrm{Kms}$. de Ilipa y de Italica: idem, SDHI 49, 1983, p. 401: una dedicatoria al (jenius del municipio Artigiense; hay dos ciudades héticas con este nombre: una de ellas estaría en Marchena (Sevilla), lugar del hallazgo.

Sobre Ostippo, vid. supra, n. 50.

7. J. Gonzále\%, AEArq. 60, 1987, pp. 2.37-250) piensa que Trajano recibió la salutación imp. $X$ y el titulo de Parthicus en el otono del a. 114 , tras la conquista de Mesopotamia del N. Este mismo epígrafe, infra, apartado II.2. Bética, con nn. 209 y 210.

${ }^{77}$ A. U. Stylow, (ierión 1, 1983, pp. 267-303 (AE 1983, n. 534): inscripción funcraria dedicada a un seruus m(unicipum) m(unicipii) Ipolcohulensium, acompañado de un estudio de la localización de varias ciudades béticas; idem, Gerión 4, 1986, pp. 303-307 ( $A E: 1986$, n. 307): reconstrucción de $A E$ 1941, n. 133; idem, $M M$ 28, 1987 , p. 57 ss., n. 50: m(unicipi) Fla(ui) Laci(---) puede referirse a Lacilhula, que tiene este 


\section{Senatores}

La hipótesis que propone como testador del hasta ahora llamado testamentum Dasumii a Cn. Domitius Tullus ${ }^{74}$, ha sido admitida por Syme; la heredera nombrada en primer lugar es Domitia Lucilla maior; $P$. Caluisius Tullus Ruso (cos. a. 109) sería también heredero, con la condicio nominis ferendi ${ }^{75}$. Más recientemente, Mme. di Vita ha ido aún más allá: partiendo siempre del esquema de herederos trazado por Eck, y aceptando la hipótesis Domitius, propone un nuevo stemma de los Caluisii Rusones, según la cual P. Caluisius Ruso, cos. suff. a. 79 y ord. a. 109 se casó (ya con el nombre Tullus introducido en su onomástica) en segundas nupcias con Domitia Lucilla maior, hija del testador y heredera principal; él sería el amicus rarissimus, nomen eius laturus, mencionado en el testamento. En el discurso de Mme. di Vita, de una lógica impecable, se sustituye la lectura [fi]lia Seruiani (que lleva la segunda heredera sustituta de la filia del testador), por [Ae]lia Seruiani; esta nueva lectura conduce a la deducción de que el primer sustituto (filius) sería nada menos que el propio P. Aelius Hadrianus; en este supuesto, conocemos ahora el nombre de la madre del Emperador: no sería otra que la rica heredera, la que también dio nombre a los horti Domitiae, donde se edificó el mausoleo de Adriano ${ }^{76}$.

Una de las familias senatoriales béticas mejor documentadas es la de los Messii Rustici; tenemos tres nuevos epígrafes dedicados a miembros de esta familia: el primero de ellos, dedicado a un hijo de Aemilius $P a-$ pus $^{77}$, asegura una nueva pareja de consules suffecti atribuibles al a.

status, o quizá a Lacippo. Una placa de bronce procedente de Andelos (Navarra): M. A. Mezquiriz, AEArq. 58, 1985, pp. 175-176, podría significar la elevación de esta ciudad a la categoría de municipio en época flavia.

A. Emborujo, CPHA (supra, n. 22): una nueva mención epigráfica de la ciudad de Suestatium.

${ }_{74}$ Propuesta que hice en I Cong. And. de Est. Clás., Actas, Jaén 1982, pp. 159163, cf. $A E 1983$, n. 516 y emerita 53, 2, 1985, p. 219. L. Migliardi Zingale, Iura 31, 1980 (publ. 1984), pp. 144-148: observaciones de carácter jurídico sobre el mismo fragmento.

${ }_{75}$ R. Syme, "The Testamentum Dasumii: some novelties», Chiron 15, 1985, pp. 41-63; cf. idem, Histoi ia 34, 1985, p. 357. E. Champlin, ZPE 62, 1986, pp. 251-255, propone nuevos suplementos para las linn. 120-124, apoyado en FIRA III. 247; este A., aunque se muestra reacio a entrar en el juego de identificaciones, parece aceptar la opinión de A. M. ${ }^{a}$ Canto, aún no publicada, que rechaza la hipótesis Domitius y propone en cambio a L. Licinius Sura; en esta hipótesis, el amicus rarissimus sería Iulius Vrsus Seruianus.

${ }_{76}$ G. De Vita, "Le testament dit 'de Dasumius': testateur et benéficiaires", EJR (supra, n. 19), pp. 159-174; idem, Des Calvisii Rusones à Licinius Sura, MEFRA 99. 1, 1987, pp 281-333: revisa la carrera de este último personaje; a él atribuye $C I L$ II $4508, I R B$ n. 29, que Alföldy (FH, p. 17) refería a Ti. Plautius Siluanus Aelianus.

77 A. Caballos y J. González, ZPE 52, 1983, p. 157 ( $A E$ 1983, n. 517). 
$136^{78}$; una segunda está dedicada por el ordo municipi Siarensis seguramente al mismo personaje que ya conociamos por CIL XIV $3516^{79}$; la tercera, fragmentaria, es de atribución dudosa ${ }^{80}$.

El origen bético de una rama de Stertinii con rango senatorio parece confirmarse con la presencia de una dedicatoria a $L$. Stertinius... hallada en Almuñécar: el epígrafe, fragmentario, informa de que el personaje desempeñó algún cargo en Asia ${ }^{81}$. A esta familia debe referirse otro epigrafe, que menciona a un L. Stertinius Quintilianus, trib. mil. leg. VII Gemina, encontrado en las cercanías de Porcuna, la antigua Obulco ${ }^{82}$.

Una dedicatoria puesta a $P$. Mummius Sisenna Rutilianus en la provincia de Sevilla, parece abogar también por el origen bético del personaje ${ }^{83}$.

Sir Ronald Syme ha desarrollado un aspecto de las premisas sentadas en su estudio sobre la llamada adopción testamentaria ${ }^{84}$, en un artículo que titula The paternity of polyonimous consuls ${ }^{85}$. Este insigne estudioso atribuye origen bético a $Q$. Fabius Postuminus, cos. suff. a. 96, y a $L$. Fabius Tuscus, recientemente descubierto como cos. suff. del a. $100^{86}$; S. Dardaine propone origen bético para la esposa de Lucano ${ }^{87}$.

La familia del ya conocido eques, Marius Octauius Nouatus, de Segobriga, fue sin duda elevada al rango senatorial en tiempo de Vespa-

${ }^{78}$ Aemilius Papus y Burbuleius Ligarianus; cf. G. Alföldy, Konsulat..., p. 225, n. 101.

${ }_{74}$ J. González, Estudios... (supra, n. 54), p. 109, n. 27.

*0 J. González, ZPE 60, 1985, pp. $145-146$ y Estudios... (supra, n. 54), p. 96, n. 5: propone la identificación del personaje con el de la inscripción de Éfeso (Éfesos 697 b), pero el epígrafe no proporciona base suficientemente firme para ello.

${ }^{* 1}$ C. Castillo, ZPE 61, 1985, pp. 219-221, con observaciones complementarias de W. Eck, ibid., pp. 222-223.

\$2 J. Serrano Carrillo y J. A. Moreno, Arq. inédita de Córdoba y Jaén, p. 165, n. 187, vid. infra, n. 91; cf. R. Portillo, P. Rodriguez. Oliva y A. U. Stylow, MM 26 , 1985, p. 198, donde se anuncia un estudio de A. U. Stylow sobre este epigrafe.

${ }^{*} 3$ J. González, ZPE 52, 1983, pp. 172-173; sugerí el origen bético de esta familia en Tituli 5, 1982, p. 511. R. Syme, ZPE 51, 1983, p. 290, propone el a. 150/151 para el proconsulado de Asia de P. Mummius Sisenna y el a. 160/161 para el de P. Mummius Sisenna Rutilianus.

${ }_{84}$ R. Syme, "Clues to Testamentary Adoption», Tituli 4, 1982, pp. 397-400. Basado en este estudio, C. Castillo, "Los senadores de la Bética: onomástica y parentesco", Gerión 2, 1984, pp. 239-250 ( $A E$ 1984, n. 499). Vid. también: R. Syme, "Spanish Pomponii: a Study in Nomenclature», Gerión 1, 1983, pp. 249-266.

${ }^{x s}$ R. Syme, ZPE 61, 1985, pp. 191-198.

s6 R. Syme, "Prefects of the City: Vespasian to Trajan», Hom. d'Ors II, Pamplona 1987, pp. 1057-1074, esp. 1069-70. Vid. también: idem, "Antistius Rusticus, a consular from Corduba", Historia 32, 1983, pp. 359-374; "Spaniards at Tivoli», Anc. Soc. 13-14, 1982-83, pp. 241-263.

77 S. Dardaine, "La gens Argentaria en Hispania», $M C V$ 19, 1983, pp. 5-16. Sobre las mujeres de familia senatorial, vid. ahora M. Th. de Raepsaet Charlier, Prosopographic des femmes de l'ordre sénatorial ( $I^{\prime}-I I^{\prime}$ siècle $), 2$ vols., Lovaina 1987. 
siano $^{\mathrm{xx}}$. Es improbable que la inscripción honorifica del foro del Ampurias, que honra a un $M$. Iun[io...] pro[...] co[...] se refiera a $M$. Iunius Silanus, como piensan sus editores ${ }^{89}$. Conocemos ahora el nombre del procónsul de la Bética en el a. 159: Lucilius Africanus ${ }^{90}$.

\section{Equites}

Un epigrafe incompleto, hallado en los alrededores de Porcuna, proporciona información acerca de una familia de rango ecuestre ${ }^{41}$; figuran alli un $Q$. Cornelius [Proculus] que fue flamen provincial, un L. Stertinius Quintilianus, trib. milit. (seguramente angusticlauius) de la Legio VII Gemina, y un [Q. Cornelius] Rusticus Apronius, que desempeñó una procuratela en la provincia: estos personajes, cuyos elementos onomásticos son los mismos que aparecen en la nomenclatura de los Stertinii de rango senatorial (apartado 7, supra), deben de ser los inmediatos antecesores de aquéllos.

Un gran bloque de mármol, con inscripción honorifica, encontrado en Córdoba y conservado fragmentariamente, honra a un C. Rocius Rocianus, que fue tribunus militum y probablemente praefectus de una cohors equitata cuyo número y nombre desconocemos. Es muy probable

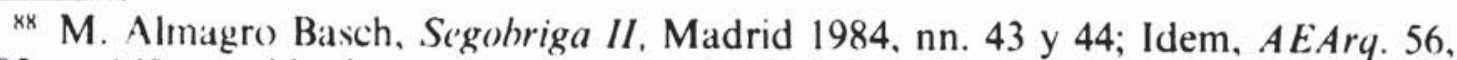
1983, p. 140 ss.; vid. al respecto: G. Alföldy, Römisches Städtew'esen auf der Ne'ukastilischen Hochebene, Heidelberg 1987, p. 83 s.

Posiblemente debe leerse un cursus senatorial en una nueva inscripción de Sagunto reconstruida parcialmente por Alföldy, vid. F. Roca, Arse 20, 1985, pp. 59-61.

Sobre inscripciones ya conocidas: G. Alföldy, "'M. Cornelius Nigrinus filius'», un hijo perdido, $A P L 17,1987$, p. 341 ss.; idem, "Cn. Papirius Aelianus Aemilianus Tuscillus', ein Senator aus Iliberris", Hom. d'Ors I, Pamplona 1987, pp. 141-149. A. Caballos, "Acilius Attianus", Hahis, 15, 1984, pp. 237-251 of rece diversas puntualizaciones sobre la vida y carrera de este personaje.

En comentario sobre una nueva estela hermaica de Cañete de las Torres (Córdoba), $A E 1984$, n. 534 ( $A E 1983$, n. 532$)$ se insinúa la posibilidad de que el personaje honrado por su dispensator fuera senador.

84 J. Aquilve 't alii, El forum romá d'Empories, Barcelona 1984, p. 129, n. 19, AE 1984, n. 615.

*) Cf. supra, n. 57; J. González, Habis 12, 1981, p. 139 ss. propone una nueva lectura de CIL II 1405, que supone a Iulius Titianus legatus de la Bética. M. Christol, $R E A 83,1,2,1981$, pp. $75-81$ puntualiza la carrera de dos gobernadores de la Citerior: $Q$. Hedius Rufus Lollianus Gentianus y L. Marius Vegetinus Marcianus Minicianus Myrtilianus, al que cree originario de la Bética.

${ }^{91}$ J. Serrano Carrillo y J. A. Moreno, Arq. inédita de Córdoha y Jaén, p. 165, n. 187: $Q$. Cornelius [Q:f. Senecio Proculus?] / flamen diuor. Au[g. pr. Baet in hon.] / Valeriae L.f. Cornelia[nae sacerd.] / Marti et L. Stertini Qu[intiliani] / trib. milit. leg. VII Gemi[n. et Q. Corneli] / Rustici Aproni procur[atoris Aug.] / prouinc. Baetic. aedem [porticum] stratam et statuas mar[moreas... (He puesto los suplementos). 
que sea el mismo personaje cuyo nombre figura en ánforas de aceite recientemente descubiertas, en posición que corresponde al propietario del producto ${ }^{92}$; Rociani, en idéntica posición, se lee en una ánfora de Testaccio, fechada en el a. 149 y con control de salida en Astigi ${ }^{93}$.

Un patronus de la Citerior, llamado $C$. Docquirus Flaccus, que aparece en una inscripción funeraria de Córdoba de redacción poco común, parece haber alcanzado rango ecuestre ${ }^{94}$.

En la provincia de Burgos se ha encontrado una dedicatoria de $L$. Antonius P.f. Quir. Aquilo, que fue tribuno de una cohorte desconocida seguramente en el s. I $^{45}$; un cursus ecuestre correspondiente a un ignotus y encontrado en Mataró, ha sido objeto de diversas lecturas ${ }^{46}$ : es el tercer eques conocido, homenajeado en esta ciudad. P. Le Roux ha vuelto sobre el procurador Saturninus de la ya conocida inscripción de Lugo ${ }^{47}$.

\section{Ejér(ito}

Es una novedad poder hablar de diplomata militaria en la Bética: dos documentos del género, hallados en esta provincia, se han publicado en el quinquenio que nos ocupa; de uno de ellos se conserva sólo la parte posterior; puede fecharse en época anterior a Domiciano, pero no se sabe el nombre ni la procedencia de su beneficiario ${ }^{98}$. El segundo

92 B. Liou y R. Marechal, Archaeonatica 2, 1978, p. 128, n. 16.

9.3 CIL XV 3871; en 3870 figura la misma marca y el nombre del diffusor Sex. Fadius Secundus.

${ }^{44}$ A. Marcos Pous, Corduha Archaeologica 15, 1984-85, pp. 69-72. Lee asi: D.M./ C'. Docquiri Flacci / Aq(uis) F(auis) e'(gregii) u(iri) / patrono pro/u. H.C. Annae/us Vernacu/lus cliens [e]t T. Iulius Pos/phorus libertus.

"5 J. A. Abásolo, BSAA 50, 1984, pp. 195-216 ( $A E$ 1984, n. 568). Quizá haya que integrar en el epigrafe del procurator Magnius Donatus (A. Canto, Habis 8, pp. 425428) un fragmento hallado recientemente en Écija (Sevilla): G. Chic y M. E. Martinez. Ortega, Gades 12, 1984, pp. 385-404 ( $A E$ 1984, n. 51).

"* Ya recogida por Devijver, Prosopographia militarum equestrium II, Lovaina 1977, p. 897, n. 9. G. Fabre y M. Mayer, Laietania 2-3, 1982-83, pp. 214-216, cf. AE 1983, n. 626, con observaciones a esta lectura.

${ }_{97} A E$ 1973, n. 294, 1976, n. 312, 1980, n. 595 bis. P. Le Roux, «Procurateur affranchi in Hispania: Saturninus et l'activité minière", $M M$ 26, 1985, pp. 218-233 ( $A E$ 1985, n. 494).

W. Eck, ZPE 41, 1981, pp. 235-236 observa que el procurator Augusti nombrado en $A E$ 1986, nn. 227-228, no puede identificarse con su homónimo de la inscripción de Afrodisias (CIG 2.792, 2.793), cf. $A E$ 1982, n. 577.

M." M. Alves Dias, Conimbriga 25, 1986, pp. 193-203 se ocupa del cursus de $Q$. Mamilius Capitolinus (CIL II 2634).

${ }_{48}$ J. González, "Diploma militare ex Baetica», Faventia 5, 2, 1983, pp. 91-95, aunque el editor propone una datación que se retrotrae a Claudio, es ésta una deducción basada en la reconstrucción que hace del texto, no del todo segura, cf. $A E$ 1983, n. 523; circunstancias de hallazgo desconocidas. 
está datado en el a. 161 y corresponde a un veterano del ejército de la Tingitana ${ }^{99}$.

Un centurión primipilo, originario de Liria (Valencia), que murió en el bellum Mauricum, tigura en un epígrafe de reciente hallazgo: Alföldy atribuye el cargo a la legio VII Gemina ${ }^{100}$. Este estudioso ha dado a conocer y revisado otras inscripciones militares de Hispania, y ha hecho una amplia recensión a la obra de Le Roux sobre el ejército romano y la organización de las provincias hispanas ${ }^{101}$. Este último autor ofrece un artículo sobre el ejército hispano y las guerras dácicas de Trajano ${ }^{102}$; también, algunas observaciones sobre el origen y la carrera del centurión de la legio VII documentado en un grafito de Roma ${ }^{103}$. A. Blanco da a conocer a un beneficiarius de este mismo cuerpo, de origen itálico y época severiana ${ }^{104}$. Varias noticias sobre la cohors I Celtiberorum publica Caamaño ${ }^{105}$; un eques alae Vettonum datable en la primera mitad del s. I, aparece en la provincia de Toledo ${ }^{106}$, y un aquilifer cuya unidad se desconoce, en inscripción cordobesa, probablemente también de época julio-claudia ${ }^{107}$.

Un nuevo terminus augustalis de la legio $X$ se ha encontrado en la

${ }^{99}$ P. Jacob, Gerión 2, 1984, pp. 325-332 y MCV 20, 1984, pp. 7-16, cf. $A E 1984$, n. 529. Algunas observaciones a su lectura e interpretación: F. López Pardo, Gerión 4, 1986, pp. 319-323. Sobre los diplomata, vid. H. Absil e Y. Le Bohec, Latomus 44. 1985 , pp. $855-870$, con bibliografia reciente.

${ }_{100}$ Hay dos publicaciones del epígrafe: J. Corell, AEArq. 149-150, 1984, pp. $177-$ 178 y G. Alföldy, Chiron 15, 1985, p. 65. Vid. infra, Apartado II.3 y nn. 267 y 268. En $A E 1985$, n. 622 se incluyen observaciones a la interpretación de Alföldy. Un estudio de las relaciones entre Hispania y la Tingitana, de Claudio a Domiciano: $M$. Cristol y P. Le Roux, Ant. Afr. 21, 1985, pp. 15-33, con motivo de CIL II 2984, cf. $A E$ 1985, n. 600 .

101 G. Alföldy, Römische Heeresgeschichte, Amsterdam 1987, pp. 514-520 ( $A E$ 1986, n. 459): nueva lectura y datación de CIL II 4322 (RIT 399), un centurión de la legio VII.

Idem, Gerión 3, 1985, p. 390: reconstrucción de $A E$ 1967, n. 237 ( $A E$ 1985, n. 579), dentro del estudio dedicado al libro de Le Roux, que ocupa las pp. 379-410; respuesta de Le Roux, ibid, pp. $411-419$ ( $A E$ 1985, n. 496).

${ }_{102}$ P. Le Roux, $M C V 21,1985$, pp. 77-79. Idem, $Z P E 43,1981$, p. 204, relectura de $A E$ 1976, n. 296.

${ }^{103}$ P. Le Roux, Epigraphica 43, 1983, pp. 73-74; vid. EMERITA 53,2, p. 224, n. 94.

104 A. Blanco, $B R A H 180,2,1983$, p. 237 ss. $(A E 1983$, n. 487). A este mismo cuerpo pertenece el dedicante de un ara a una divinidad indígena: vid. F. Patricio Curado, $F E 11,1985$, n. 44 ( $A E$ 1985, n. 524).

${ }_{105}$ J. M. Caamaño, Not Arq. Hisp. 18, 1984, pp. 233-254 (AE 1984, nn. 549551). Idem, Brigantium 4, 1983, pp. 61-71 ( $A E$ 1986, n. 387).

${ }_{106}$ S. Cortés et alii, Museos 3, 1984, pp. 74-75, n. 3.

107 A. Marcos Pous, APL 17 (Hom. a Fletcher Valls I), 1987, pp. 367-382: M. Septicius C.f. Pap. / aquilifer, sibi et M. Sabi[na]e / contubernali suae et M. Sep[tici]o / M. liberto Martiali filio naturali [ann.] X / et mensum VII / H.s.s.s.u.t.l. / post eorum obitum / hoc monimentum hered[em] / non sequetur. 
provincia de León, a $19 \mathrm{kms}$. del campamento de Rosinos de Vidriales ${ }^{108}$; en el mismo campamento se ha encontrado una marca $L X G$, fechable en la segunda estancia de esta unidad en Hispania, entre los a. $68 / 70^{109}$. Varios autores se han ocupado de epígrafes militares ya cono$\operatorname{cidos}^{110}$.

\section{Flamines $y$ pontifices}

Desde 1966 conocemos al primer flamen provincial de Lusitania que puede datarse con seguridad, en razón de la fecha consular que cierra el epígrafe: $\left[A\right.$. Vitel]lio L.f. C. Vipstano [-f.] cos. ${ }^{111}$; el epígrafe se ha atribuido al a. 48; pero una foto reciente ${ }^{112}$ deja ver claramente que el praenomen del segundo cónsul era $C$ (aius), mientras que el del cónsul del a. 48 era $L$ (ucius). El único $C$. Vipstanus cónsul ordinario es $C$. Vipstanus Apronianus, colega de C. Fonteius Capito en el a. 59, pero esta posible enmienda de la datación choca con la filiación documentada en nuestra inscripción para el primer cónsul: $L . f$. siendo así que los Fonteii Capitones llevan el praenomen $C$.; un rompecabezas de praenomina para el que seguramente la mejor solución será pensar que el lapicida de la inscripción lusitana se equivocó. De un nuevo flamen Romae/... que figura en inscripción de Segobriga, conocemos solamente el praenomen, y el cognomen de su hija: Auita ${ }^{113}$; hay una remota posibilidad de que se trate de C. Iulius C.f. Gal. Pila (CIL II 4222), segobri-

${ }^{108}$ M. Descocido, Tierras de León, 48, 1982, pp. 95-96 ( $A E$ 1982, n. 578). Marcas de esta legión y de la VI Victrix y la IV Macedonica, encontradas en sillares del puente de Martorell, confirman la participación de estas unidades en trabajos de acondicionamiento de comunicaciones en la Tarraconense oriental en época de Augusto, vid. G. Fabre, M. Mayer e I. Rodá, Épigraphie Hispanique, Paris 1984, pp. 282-288. Sobre esta cuestión, vid. emerita $53,2,1985$, pp. 223 , n. 23, y 228, n. 121.

${ }_{109}$ J. Hahl, $M M 25,1984$, p. 72 ss. ( $A E 1984$, n. 555). Algunos ladrillos y tegulae con marcas de la legio VII se han hallado recientemente en León: J. M. Vidal Encianas, Archiv. León 76, 1986, pp. 365-380.

${ }^{110}$ M. P. Speidel, Gerión 3, 1985, pp. 347-348 ( $A E$ 1985, n. 491), sobre CIL III 3271 , dedicada a un decurión del ala II Arauacorum, domo hispano; Britto está documentado en Mérida y en la Bética occidental; cf. J. Untermann, Atlas antroponimico... Madrid 1965, mapa 19.

J. Pons Sala, Auza 10, 1982, pp. 319-328 se ocupa de CIL XIII 6858: un Ausonensis, miles de la legio IIII Mac.; J. Gómez Pantoja, ZPE 68, 1987, pp. 232-236 revisa la lectura de dos epigrafes militares de la provincia de Soria.

III $A E$ 1966, n. 177, reproduce la inscripción a falta del praenomen de Vipstanus. Otro error en el praenomen de un cónsul, en la tabla de patronato de Montealegre (supra, n. 62).

112 M. D. Girão de Cauz, Arqueología 14, 1986, pp. 115-121.

113 M. Almagro Basch, Segobriga II (Exc. Arq. 127), Madrid 1984, n. 134. 
gense honrado en Tarraco como flamen Romae diuorum et August. prou. Hisp. Citer. A una flaminica provincial de la Citerior parece dedicada una pieza reutilizada hallada en Tortosa ${ }^{114}$.

En la lista de flamines provinciales de la Bética, hay que añadir a $M$. Cassius Caecilianus, italicense adscrito a la tribu Sergia, que después de ser flamen perpetuus diui Traiani en la colonia, fue flaminalis de la provincia; el personaje, que debió de ser contemporáneo de Adriano, pone cuatro estatuas ob honorem Iluir(atus) ${ }^{115}$; su dedicación al Genio de la colonia es la primera que se encuentra en Italica, y también es ésta la primera mención que tenemos de un flaminato del diuus Traianus en la Bética; propone A. M. ${ }^{a}$ Canto ${ }^{116}$ la identificación de este personaje con un Caecilianus, adlectus ab imp. Traiano de otro fragmento italicense, y lo convierte en uir consularis; más probable es la promoción de esta familia al rango ecuestre.

A la época anterior, en la que Italica era aún municipio, pertenece L. Herius L.f., que tras obtener la potestad duoviral por tres veces, fue pontifex creatus Augusto primus: una mención que es paralela a la de los personajes de la inscripción monumental encontrada en el teatro, cuya cronologia aclara este nuevo hallazgo ${ }^{117}$. La lectura que ahora se hace de $A E 1981$, n. 501 revela a un nuevo pontifex de Sosontigi ${ }^{118}$. Una flaminica de origen mauretano hace una importante donación en Italica ${ }^{119}$; la expresión iterato honore bis flaminica sacerdos parece dar a entender que las denominaciones se acumulan en un único honor; puede datarse a finales del s. II o ya en el s. III. También en la colonia italicense se do-

114 M. Mayer e I. Rodá, Fonaments 1984, p. 171 (AE 1985, n. 626); I. García Jiménez, Anales de Prehist. y de Arq. (Univ. de Murcia) 1, 1985, pp. 133-135, atribuye un epígrafe fragmentario de Cartagena (A. García y Bellido, $B R A H$ 168, 1971, p. 204, n. 28 cf. A. Beltrán y P. A. San Martín, Act. XVI CNA, p. 872) a L. Numisius Laetus, flamen de la Citerior.

115 P. León, Exc., Arq. Esp. 121, 1982, p. 171, n. 1 ( $A E$ 1982, n. 520); A. Blanco Freijeiro, $B R A H 180,1,1983$, pp. $1-19(A E 1983$, n. 519).

116 A. M. Canto, ERI (supra, n. 25), n. 22 bis y n. 66. Sobre el personaje y sus posibles relaciones con otros notables béticos, vid. infra, n. 213.

117 A. Blanco Freijeiro, $B R A H 180,1983$, p. 14 ( $A E$ 1983, n. 522). De este epi-

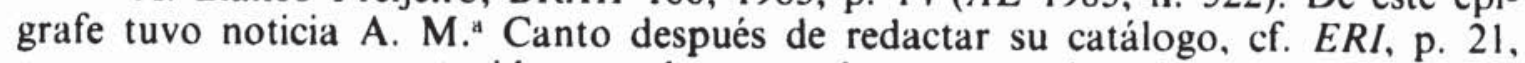
pero no conoce su contenido completo, por lo que mantiene la cronología tardía para los epigrafes primi creati Augusto de la inscripción monumental del teatro (ERI, n. 49). Comenté este epígrafe en mi crónica anterior (EMfrita 53,2, 1985, pp. 224225). Para los pontífices de la Bética, vid. mi comunicación al coloquio AIEGL celebrado en Tarragona, oct. 1988 (actas en prensa).

118 A. U. Stylow, Gerión 1, 1983, p. 282 ( $A E$ 1983, n. 536); vid. también Los pontifices de Bética (cit. supra, n. 117).

119 P. León, Exc. Arq. Esp. 121, 1982, p. 117, n. 2 (AE 1982, n. 521); otra lectura con algunas variantes: A. Blanco Freijeiro, $B R A H 180,2,1983$, p. 8 ( $A E 1983$, n. 521 ); vid. A. M. ${ }^{a}$ Canto, ERI, n. 22 ter. 
cumenta ahora un augur perpetuus, que reviste este cargo después de haber desempeñado magistraturas civiles; Blanco lo fecha a mediados del s. II ${ }^{120}$; se ve que por estas fechas el carácter de perpetuidad no era ya, como en un principio, inherente al cargo de augur: no se entiende si no qué sentido tendría hacer constar que era perpetuus, a no ser que se trate de una redundancia que subraya el honor alcanzado.

\section{Epigrafia prerromana. Cultos y onomástica indigenas}

En el Coloquio sobre Epigrafia Hispánica de Época Republicana celebrado en Zaragoza, se presentaron dos ponencias sobre epigrafia prerromana: la de Siles, sobre la epigrafia ibérica ${ }^{121}$, y la de J. de Hoz so-

120 A. Blanco Freijeiro, BRAH 180,1, 1983, p. 7 ( $A E$ 1982, n. 520). No está en ERI. Sobre su posible relación con otros personajes béticos, vid. infra, n. 212. Sobre los augures, vid. J. Mangas, "Augurationes et augures' en la Hispania romana», Act. de la II Jornada de Metodología y Didáctica de la Historia, Cáceres 1984, pp. 87-104: interpreta, como ya hacia Êtienne, la secuencias pontifex aug. como pontifex, augur; opinión de la que difiero (cf. "Los pontífices de la Bética», cit. supra, n. 117); A. M. ${ }^{a}$ Vázquez Hoys, Dianium 1, 1983, pp. 51-63, llama la atención sobre los Salii documentados en Sagunto.

M. A. Rabanal y J. M. Abascal, Lucentum 4, 1985, pp. 191-244; un seuir en la provincia de Alicante. A. U. Stylow, $M M$ 28, 1987, p. 119, n. 4: un seuir Augustalis perpetuus en la Bética; sobre esta titulatura, vid. R. Duthoy, $A N R W$ II 16,2, p. 1270 , n. 118.

121 J. Siles, "Sobre la epigrafia ibérica», EHER (supra, n. 21), pp. 43-102. Sobre la lengua ibérica: J. Untermann, Hom. Fletcher Valls, Valencia 1984, pp. 249-272. Otros estudios lingüisticos: J. Untermann, "Die althispanischen Sprache», $A N R W$ II 29,2, 1983, pp. 791-818; J. de Hoz, "Las lenguas y epigrafia prerromana de la Península Ibérican, Actas VI Congr. Esp. Est. Clás., Madrid 1983, pp. 351-396; J. Best, "Zur frühindoeuropeischen Sprache in Lusitanien», Talanta 13, 1981, Suppl. Epigr. Mediterraneum, pp. 63-68; A. Tovar, "La inscripción del Cabeço das Fraguas y la lengua de los lusitanos", Actas del III Col. LCP (supra, n. 18), pp. 227-254; J. Untermann, "Los teónimos de la región lusitano-gallega como fuente de las lenguas indigenas", ihid., pp. 343-364 (AE 1985, n. 498); idem, Symbolae I (Hom. Mitxelena), pp. 433-439: se ocupa de nuevas inscripciones en la provincia de Gerona; idem, "Nuevos textos ibéricos sobre plomo", Act. Num. 15, 1985, pp. 33-46. Sobre los tituli picti en caracteres ibéricos de las ánforas de Vieille Toulouse: M. Vidal y J. P. Magnol, RANarh. 16, 1983, pp. 1-28 y F. J. Oroz, Act. IV Col. LCP (supra, n. 18), pp. 355-370.

Otras inscripciones ibéricas nuevas: A. Oliver et alii, Cuad. de Preh. ${ }^{a}$ y Arq. Castellonense 9, 1982-83, pp. 243-248; D. Fletcher Valls, Arse 18, 1983, pp. 8-10 y 19. 1984, pp. 4-11; A. Oliver, Saguntum 20, 1986, pp. 117-12; M. M. Medrano y M. A. Díaz, Hom. A. Beltrán, Zaragoza 1986, pp. 601-609. Sobre la estela de Caste (Habis 10-11, 1979-80, pp. 401-420), vid. G. López Monteagudo, AEArq. 56, 1983, pp. 261268 y M. Pérez Rojas, ibid., pp. 269-285.

Una inscripción en escritura tartesia: M. García Pereira y J. A. Correa, Habis 16 , 1985, pp. 243-274; J. A. Correa, Consideración sobre las inscripciones tartesias, Actas II Col. LCP (supra, n. 18), pp. 377-396. 
bre epigrafia celtibérica ${ }^{122}$ : repasa esta última las diversas clases de epigrafes que produjo esta cultura, y dedica un apartado a la organización social de los celtíberos según los testimonios epigráficos.

Le Roux y Tranoy han vuelto sobre la interpretación del signo $\supset^{123}$; un corpus de inscripciones del área indoeuropea de la Península, en las que se mencionan unidades suprafamiliares, ofrece $\mathrm{M}^{\mathrm{a}}{ }^{\mathrm{C}} \mathrm{C}$. González $^{124}$. Se han dado a conocer tres nuevas tesserae hospitales celtibéricas ${ }^{125}$.

En lo que respecta a la onomástica personal, se han seguido publicando estudios de M. ${ }^{\text {a }}$ L. Albertos ${ }^{126}$; Untermann ha hecho un ensayo

122 J. de Hoz, "Sobre la epigrafia celtibérica», EHER (supra, n. 21), pp. 43-102.

${ }_{123}$ P. Le Roux y A. Tranoy, Hom. Pinho Brandão, pp. 239-255; iid., AEArq. 56, 1983, pp. 109-121 ( $A E$ 1984, n. 539): sobre esta discusión, vid. infra, Apartado II.3, con nn. 236 y 237.

Nuevos epigrafes con este signo publican: J. Mangas y E. Matilla, Mem. H. ant. 5, 1982 (1983), pp. 253-256; G. Pereira, Veleia 1, 1984, p. 281 ( $A E$ 1984, n. 552). Sobre los castella del N-O peninsular, M. ${ }^{a}$ L. Albertos, Actas CPHA (supra, n. 22), pp. 191-196.

${ }_{124}$ M. ${ }^{a}$ C. González, Mem. H. ${ }^{a}$ Ant. 7, 1986 (1987), pp. 50-80 (no incluye ninguna de Portugal); eadem, Las unidades organizativas indigenas del área indoeuropea de Hispania, Vitoria 1986 ( $A E$ 1986, n. 276). G. Pereira y J. Santos, "Ensayo de sistematización de la epigrafia romana de Asturias: las unidades gentilicias", BIEA 105-106, 1982, pp. 87-110: un total de 70, pertenecientes al territorio de los Gallaeci, Astures y Cantabri. Un nuevo punto de vista ofrece F. Beltrán, "Un espejismo historiográfico: las "organizaciones gentilicias" hispanas", Actas CPHA (supra, n. 22), pp. 197-238. Nuevas gentilidades: G. Alföldy, St. in hon. I. Kajanto, Arctos Suppl. II, 1985, pp. 9-14: Solicum; M. M. Donas Botto, $F E$ 16, 1986, n. 71 (interpretada en $A E$ 1986, n. 298 como límite de propiedades); M. Garcia Garrido y J. Pellicer, Kalathos $3-4,1983$, pp. 149-154. Otras tres tesserae ya conocidas recoge M. Almagro Basch, Segobriga II, Madrid 1984 (Exc. Arq. 127), pp. 10-20: P. Palol y J. Vilella, Clunia II (Exc. Arq. 150), Madrid 1987: tres epígrafes en lengua celtibérica, uno de ellos inédito.

Nuevos termini territoriales entre unidades gentilicias: A. Rodriguez Colmenero, Actas $C P H A$, pp. 271-290.

${ }_{125}$ C. Garcia Merino y M." L. Albertos, Actas III Col. LCP (supra, n. 18), pp. 311-318.

${ }_{126} \mathrm{M} .{ }^{a}$ L. Albertos, "Onomastique personnelle indigène de la Péninsule Ibérique sous la domination romaine", $A N R W$ II 29, 2, 1983, pp. 853-892 ( $A E$ 1983, n. 460); eadem, Est. Arq. Alavesa 2, 1985, pp. 365-377 ( $A E$ 1985, n. 580); eadem, "La onomástica personal indigena de la región septentrional», Act. IV Col. LCP, pp. 155194; eadem, «La onomástica personal indígena del N-O peninsular (astures y galaicos)", Act. III Col. LPC, pp. 255-310.

Otros estudios: M." C. González, "Sobre el sistema onomástico indígena del área ide. de Hispania», Act. CPHA (supra, n. 22), pp. 263-270: M." M. Alves Días, Symbolae I (Hom. Mitxelena), pp. 537-562 y 563-564; eadem, Actas IV Col. LCP, pp. 195-203.

Nombres nuevos: J. Abásolo, AEArq. 58, 1985, pp. 159-174 ( $A E$ 1985, n. 586): Alebbius, [B]odamo; A. E. Maia do Amaral, FE 23, 1987, n. 107: Tulorus; E. Isla Bolaño, Museos 1, 1982, p. 69: Arcaum ( $A E$ 1986, n. 389: Arcanum, gen. pl.).

Al N. de la provincia de Córdoba se han hallado inscripciones con onomástica 
de interpretación de las inscripciones sepulcrales ibéricas, basándose en la comparación con la estructura de los epitafios latinos: incluye un apéndice de antropónimos ${ }^{127}$. J. Hildebrand ofrece un catálogo de las monedas antiguas de Hispania conservadas en la Universidad de Giessen ${ }^{128}$.

Nuevas aportaciones referidas a las religiones primitivas están recogidas en la monografia de Blázquez Primitivas religiones ibéricas ${ }^{129}$. Rodríguez Colmenero da a conocer 12 teónimos nuevos en inscripciones de Aquae Flauiae ${ }^{130}$. J. Mangas publica cinco inscripciones del Bierzo,

común en el ámbito luso-galaico, cf. A. U. Stylow, $M M 27,1986$, p. 235 ss. ( $A E$ 1986, nn. 338 y 339); también en la provincia de Córdoba, una liberta con cognomen romano, cuyo patrono lleva cognomen indigena: A. U. Stylow, $M M$ 28, 1987, n. 57; cognomina nuevos, ibid. n. 52 y n. 64 a.

127 J. Untermann, Cuad de Preh.a y Arq. Castellonenese 10, 1984, pp. 11-119, anuncia un repertorio de antroponimia ibérica, que publicará en $A P L$.

128 J. Hildebrand, Acta Num. 12. 1982, pp. 53-57. Otras leyendas monetales: J. A. Correa, Numisma 32, 1982, pp. 69-74; A. Deroc y J. Cl. Richard, Acta Num. 12. 1982, pp. 127-130.

129 Vol. II: Religiones prerromanas, Madrid 1983: contiene las novedades que el mismo A. incluia en ATHLON II (Hom. Adrados), Madrid 1987, pp. 69-84: aunque el libro es de fecha más antigua, recoge documentación que no estaba disponible en la fecha de entrega del artículo.

Además de la ponencia de Knapp en el VIII Congr. Int. de Epigr. Gr. y Lat. (supra, n. 11), estas Actas contienen: J. M. Iglesias, "Latinisation et théonimie préromaine de la corniche cantabrique»; y J. L. Ramírez, "Les croyances religieuses, dernière survie des traits propres a l'idiosyncrasie des peuples cantabres et astures».

Otros estudios: S. Crespo, «Fuentes epigráficas para el estudio de las formas religiosas en el 'conventus Cluniensis' durante la época romana", ATHLON II, pp. 191223: reproduce 146 epigrafes ya conocidos, sin revisión de lecturas; A. Tranoy, "Énigmes épigraphiques et nouveaux cultes indigènes dans le conventus de Braga", Rev. Guimarães 94, 1984, pp. 443-449; M. P. Rodriguez A.: "Sincretismo de la religión indigena y la romana a través de las estelas antropomorfas", Brigantium 2, 1981, pp. 73-82.

${ }_{130}$ A. Rodriguez Colmenero, Act. IV Col. I.PC (supra, n. 18), pp. 327-354; la interpretación que propone de $C I L$ II 2,476 , entendido como un pacto, no está justificada.

Otras nuevas inscripciones con nombres de divinidades indigenas: A. I. de Sa Ferreira, $F E$ 16, 1986, n. 71: Lurunus; J. d'Encarnação, ibid. 14, 1985, n. 59: Triborunnis; idem, Conimbriga 22, 1983, p. 219: Quangeio Tango; idem y R. Carvalho, Belver ao tempo dos romanos, Portalegre 1984, n. 2: Ban(d) eipigius ( $A E$ 1984, n. 468); J. L. Melena, Symbolae (Hom. Mitxelena), pp. 475 ss. (AE 1985, n. 540): Arentius; y tres aras dedicadas a Salama, relacionado con el topónimo correspondiente; sobre este relación teonimia/toponimia, vid. M. ${ }^{a}$ L. Albertos, ibid., pp. 469-474; M. Mayer e I. Rodá, Fonaments 5, 1984, p. 181: Seitundo (dat.); A. U. Stylow, Gerión 1, 1983, p. 296: Daeuae (dat.) ( $A E$ 1983, n. 541); F. Patricio Curado, $F E 7$, 1984, n. 27: Equotullaicensis (epiteto de Arentia) ( $A E$ 1984, n. 479); M. Leitão, Treharuna 1, 1984, n. 32 ( $A E$ 1984, n. 475): una inscripción enigmática; en la provincia de Badajoz, un nuevo apelativo de Júpiter: Cadaris, que puede relacionarse con el antropónimo Caderus y con la gentilitas Cadarigum, vid. A. U. Stylow, $M M 28,1987$, n. 56; en $A E 1984$, n. 458 , a propósito de R. y M. V. Gomes, Conimbriga 23, 1984, p. 47. se señala la posi- 
todas ellas votivas, con lecturas sujetas a revisión, atribuidas a Cosus, con diferentes apelativos ${ }^{131}$. J. L. Melena ha hecho un estudio sobre Nabia, divinidad de la que M. ${ }^{a}$ B. García presenta una nueva interpretación ${ }^{132}$.

\section{Vias y miliarios}

El N.O. sigue siendo zona rica en hallazgos de piedras miliarias, preferentemente de época tardia ${ }^{133}$. Dos estudios recientes - uno de $\mathbf{J}$. Arce ${ }^{134}$, otro de P. Sillières ${ }^{135}$ - se ocupan de la problemática que plantean estas piezas de última épocá ${ }^{136}$.

ble relación de Castello Durhedense con el dios Duruedicus. Otros varios teónimos en epigrafes de Bracuraugusta, vid. $A E$ 1983, nn. 558, 560 y 562.

131 J. Mangas, Mem. de $H . "$ Ant. V, Oviedo 1983, pp. 253-271 (AE 1983, nn. 591595). Quizá otra variante de Cosus, P. Carvalho, $F E$ 16, 1986, n. 70 ( $A E$ 1986. n. 283). Acerca de Helasse, documentado en Alava, vid. J. Gorrochategui, Veleia I, 1984, pp. 261-265.

132 J. L. Melena, Veleia 1, 1984, p. 238 ( $A E$ 1984, n. 494): A(ugustae) / Nahiae / uictor / Sempr(oniu)s / a.l.u.s., supone una inversión del orden normal de los elementos, incluso en la fórmula votiva. M. B. García, Act. CPHA (infra, n. 22), pp. 249262. Nuevas dedicatorias a esta divinidad: C. Herrera y J. Gil Montes, El Brocense' 2.2, 1983-84, pp. 37-41 (vid. Veleia 1, 1984, p. 259) ( $A E$ 1984, n. 496).

Otras revisiones: G. Pereira, Symbolae (Hom. Mitxelena), pp. 531-535: sobre CIL II 2419; S. Santamaría, Mem. H. ${ }^{a}$ Ant. V, 1982 (1983), pp. 125-130: en lugar de Lapa(thus) propone la(res) pa(trii); J. Cardim Ribeiro, Act. IV Col. LPC, pp. 331-325: lectura de ILER 721, falso teónimo; C. Callejo, Hom. Sáenz de Buruaga, pp. 329337: deben suprimirse Dulouius y Aiuossianeius, producto de malas lecturas. 192.

Otras dedicatorias a divididades indigenas, infra, apartado II.1, Lusitania, con $\mathrm{n}$.

133 L. dos Santos, P. Le Roux y A. Tranoy, Bracara Augusta 83-84, 1983 p. 199 ss., nn. 29-33 ( $A E$ 1983, nn. 573-577): varios miliarios tardios, entre ellos un testimonio de la restauración de la vía Bracara-Lucus entre los a. 364/375; A. Rodriguez Colmenero, Arqueologia 9, 1984, pp. 117: dos inéditos de Chaves; uno de Decio, con punto de partida en Aquae Flauiae (lectura provisional) ( $A E$ 1984, n. 547); T. Mañanes, Epigrafia y Numismática de Astorga romana, Salamanca 1982, p. 135 (AE 1982, n. 576): a Valeriano y Galieno; A. Coelho y F. de Silva, Portugalia 2-3, 1981-82, p. 90: hallazgo del original correspondiente a $C I L$ II $2477=5616(A E$ 1983, n. 586); A Soto y M. Vidal, Bol. Aur. 13, 1983, pp. 173-176: sobre la historia del miliario de Vilar (Pontevedra).

134 J. Arce, «Los miliarios tardorromanos de Hispania: problemática histórica y epigrafia", Épigraphie Hispanique (supra, n. 2), pp. 289-290.

${ }_{135} \mathrm{P}$. Sillières, "De la borne milliaire à la dédicace impériale: l'exemple de quelques inscriptions routières de l'Hispanie méridionale", $R E A$ 88, 1986, pp. 351-358: dos miliarios de la tetrarquia tienen una redacción que anuncia ya las dedicatorias honorificas de s. IV.

136 M. Mayer e I. Rodá, Fonaments 5, 1984, p. 176 ( $A E 1985$, n. 630): uno de Constantino II, César, entre los a. 317/337; a otro, quizá de Constantino II, se superpone uno de Constancio II, cf. G. Chic y E. Martínez O., Gades 12, 1984, p. 402 ss., n. $10(A E 1984$, n. 522). En la via Ehora-Pax Iulia, P. Sillières, C'onimbriga 23, 
Un miliario de Adriano, prácticamente inédito, y fechado en el a. 121, encontrado entre Collipo y Eburobrittium, presenta la peculiaridad de la indicación fecit en lugar de restituit que tienen otros muchos del mismo año en la vía Emerita-Asturica ${ }^{137}$. De la vía CaesaraugustaPompaelo se conocen hasta ahora 19 miliarios ${ }^{138}$ : el de más reciente descubrimiento es de Tiberio, a. 32, como otros de la misma vía ${ }^{139}$.

Varios estudios se ocupan de vías que atraviesan el territorio correspondiente a la Meseta Sur (Castilla-La Mancha) ${ }^{140}$. Dos nuevos miliarios de la Via Augusta se han encontrado cerca de Sagunto ${ }^{141}$; al tramo que pasaba por Corduba se atribuye otro de Nerón ${ }^{142}$; a otra vía que correría al Sur de la Augusta pertenece un gran bloque de época de Claudio $^{143}$. Sobre el topónimo Cetraria ${ }^{144}$, que figura en el Anónimo de

1984, pp. 55-67 ( $A E$ 1984, nn. 466-467): uno inédito atribuido a Crispo, a. 317/326, otro revisado de Maximino Tracio.

G. Alföldy, ZPE 58, 1985, pp. 169-162 ( $A E$ 1985, n. 543) da nueva lectura de HAEpigr. 1785; M. Molina, Sodalitas 2, 1981, pp. 285-292 da como inédito uno ya publicado por M. Christol y P. Sillières ( $A E$ 1983, n. 607).

137 V. Gil Mantas, Conimbriga 25, 1986, pp. 213-225; R. Carvalho, FE 25, n. 114 uno atribuible a Domiciano, que indica la distancia a partir de Emerita; ibid. n. 115: de Severo Alejandro, a. 222/225. A un camino vecinal del conuentus Scallabitanus debe de pertenecer el texto: Asianic(enses) uia $(m)$ feccerunt, datable en el s. II, vid. $F E$ 11, 1985, n. 48 ( $A E 1985$, n. 523).

${ }_{138}$ M. C. Aguado y T. Lostal, Caesaraugusta 55-56, 1982, pp. 175-197 (AE 1984, nn. 583-585): 18 miliarios, no todos bien reproducidos; inéditos: $n$. 11, Adriano; $n$. 15, fragm.; n. 16, Constantino I; n. 17, a. 268-270. J. J. Sayas y L. Sánchez Real, Norba 2, 1982, p. 173: uno de Constancio, en la provincia de Cáceres.

${ }_{139}$ J. Lostal y A. López Armisén, Bol. Mus. Zaragoza 4, 1985, p. 320 ss. En la provincia de Soria: M. J. Borobio y J. Gómez Pantoja, Celtiheria 74, 1987, pp. 239258: uno de Decio, en Tiermes; otro de Licinio, en Burgo de Osma; J. A. Abásolo, Est. Arg. Alavesa 11, 1983, pp. $427-439$ da a conocer uno de Póstumo, en la provincia de Álava.

140 Al estudio de M. Mariné, "Las vías romanas de la provincia de Madrid», I Jornada de estudios sobre la provincia de Madrid, Madrid 1980, pp. 94-97, se unen ahora: J. M. Abascal, Vias de comunicación romanas de la provincia de Guadalajara, Guadalajara 1982 (cf. Rev. Arq. 3, 1982, pp. 60-64); S. Palomero, "Las vías romanas de Segóbriga", Hom. Almagro III, Madrid 1983, pp. 247-261: 6 miliarios de la vía Complutum-Carthago Noua; J. J. Pérez Avilés, Oretum 1, 1985, p. 188 ss.: en Almedina (provincia de Ciudad Real), uno de Trajano y otro de Antonino Pío, a. 143.

${ }_{141}$ F. Arasa e I. Gil, Centre d'estudis de la Plana 10, 1987, p. 63 ss.

142 A. U. Stylow, $M M$ 27, 1986, p. 275: nueva lectura de CIL II 2347 ( $A E$ 1986, n. 368).

${ }_{143}$ J. F. Rodríguez Neila, Habis 14, 1983, pp. 153-162 (AE 1984, n. 532): seguramente pertenece a un puente; la piedra no procede necesariamente del lugar en que se descubrió.

${ }_{144}$ P. Sillières, Épigraphie Hispanique (supra, n. 2), pp. 270-281; este A. anuncia un trabajo de conjunto sobre las vías de comunicación en el Sur de Hispania. Otros trabajos: Vias romanas del Sureste, ed. A. González, Actas del Simposio celebrado en Murcia 1986; J. L. Escacena, "Antiguas vías de comunicación en el Bajo Guadalquivir», Gades 9, 1982, p. 147 ss.: simple inventario de yacimientos; P. Sillières, "Via 
Ravenna, escribe P. Jacob, que lo sitúa en la zona del Estrecho, quizá Algeciras ${ }^{145}$.

\section{Economía y comercio: marcas de ánforas; instrumenta varia}

Decididamente, el estudio de la epigrafia anforaria y el de las rutas comerciales de las ánforas hispanas ocupa un plano de actualidad: a los trabajos de Rodríguez Almeida sobre el Testaccio, que ya eran numerosos en el quinquenio anterior ${ }^{146}$, vienen a unirse otras obras que se ocupan de la dispersión de las ánforas y de sus marcas; entre ellas destacan las de J. Remesal ${ }^{147}$ y G. Chic ${ }^{148}$ : aportan listas ordenadas y bastantes completas, que constituyen una buena base para un trabajo de interpretación de lecturas e identificación de personajes, aún no sistemáticamente acometido, cuya necesidad se hace sentir ${ }^{149}$.

En las Actas del II Coloquio sobre Producción y Comercio de Aceite en la Antigüedad, se incluyen también algunos trabajos directamente relacionados con la epigrafia ${ }^{150}$. Siguen descubriéndose nuevos depósitos

romana y villae en la zona de Palma de Condado (Huelva)", Habis 12, 1981, pp. 409-418: ningún miliario.

145 P. Jacob, $M C V$ 21, 1985, pp. 57-59.

146 Cf. emerita 53, 2, 1985, p. 231 con n. 131. Posteriormente: "Altri mercatores dell'olio betico", Dialoghi di Archeologia 1, 1983, pp. 79-86; Il monte Testaccio, ambiente, storia, materiali, Roma 1984, en cuya 3." parte incluye la epigrafia de las ánforas olearias de la Bética.

147 J. Remesal, La 'annona militaris' y la exportación del aceite bético a Germania, Madrid 1986, que incluye un corpus de cerca de 300 sellos de ánforas Dressel 20; rec. Gnomon 59, 6, 1987, p. $562 \mathrm{~s}$. El interés de este A. por temas económicos y comerciales estaba presente ya en estudios anteriores: «Die Ölwirtschaft in der Provinz Baetica. Neue Formen der Analyse», Salzburg. Jahrbuch (Mainz) 38, 1982, pp. 3071; «Ölproduktion u. Ölhandel in der Baetica: ein Beispiel für die Verbindung archäologischer u. historischer Forschung», Münstersche Beiträge zur antiken Handelgeschichte 2, 2, 1983, pp. 91-111.

Sobre la difusión de ánforas béticas en. Panonia: D. Gabler y M. H. Kelemen, AEArq. 57, 1984, pp. 121-142. Sobre la difusión del aceite bético en otros lugares, vid. Actas del Coloquio sobre Producción y comercio del aceite en la Antigüedad (supra, n. 18).

148 G. Chic, Epigrafia anfórica de la Bética I, Sevilla 1985, con un amplio indice de marcas de ánforas Dressel 20,19 y 23 . Con posterioridad al período aquí contemplado, este $\mathrm{A}$. ha publicado un segundo volumen, dedicado a los tituli picti, con un método de trabajo que ha superado ya algunos defectos de principiante que se observan en el primer volumen.

M. Martínez, Ilerda 47, 1986, pp. 135-144 da noticia de una matriz de bronce con la leyenda $C$. Valeri Leonae, conservada en el Museo de Cervera y procedente
de la Bética.

${ }^{149}$ En esta línea se preparan actualmente dos trabajos bajo mi dirección en la Universidad de Navarra.

150 Vid. supra, n. 18. 
tanto de ánforas béticas ${ }^{151}$, como de las procedentes de la región catalana ${ }^{152}$.

La marca $P$. Rocius Cleantus, Iponobensis, encontrada en el cerro del Minguillar ${ }^{153}$, se refiere seguramente al figlinarius, que debía ser un liberto de la familia de Rocius Rocianus, propietario de un fundus y exportador de aceite ${ }^{154}$, que puede identificarse con el tribunus militum de una inscripción cordobesa de la segunda mitad del s. II ${ }^{155}$. La diferencia de praenomina entre éste y Cleantus hace pensar que este último no era liberto del tribunus cordobés, aunque dada la rareza del nomen y la proximidad de los lugares de hallazgo, es inevitable relacionarlos.

F. Mayet ha abordado el problema que plantea la palabra fligina que se encuentra en ánforas Dressel 20: se pregunta si el sentido es idéntico al que tiene en las fuentes literarias y en las marcas de ladrillos, y concluye que esta palabra alude a los profesionales de la producción cerámica: algunos tienen estrecha relación con los propietarios de fundi, otros pertenecen a familias de negotiatores ${ }^{156}$.

Un nuevo mercator olearius de la Bética se documenta en un titulus procedente de Lausanne ${ }^{157}$. Una inscripción de la provincia de Sevilla da el nombre de un diffusor olearius de origen Olisiponense ${ }^{158}$; otra, de Barbesula (prov. Cádiz), menciona a un C. Iulius Alfius Theseus que debe identificarse con el mercator olearius atestiguado en tituli picti del Testaccio fechados en el a. $154^{159}$.

151 B. Helly, A. le Bot, Helly y B. Liou, «Un dépot d'amphores Dressel 20 à inscriptions peintes découvert a Sainte Colombe (Rhône)", Archaeonautica 6, 1986, pp. 121-145; D. Fonquerle, Ampurias 44, 1982, pp. 121-131.

152 D. Colls, "Les amphores léétaniennes de l'épave Cap Béar III", REA 88, 1986, pp. 201-214.

Estudios sobre ánforas de origen catalán: S. J. Keay, Late Roman amphorae in the western Mediterranean, Oxford 1984 (nueva tipologia: de fin del s. II al s. Iv), cf. rec. Latomus 47, 1988, pp. 201-205; R. Pascual, Riv. St. Lig. 46, 1980, pp. 261-279; idem, Laietania 1, 1981, pp. 197-199; J. Miró, Laietania 2-3, 1982, pp. 228-244; J. M. Nolla y J. M. Solías, "L'amfora tarraconense I", Butlleti Arq. Tarragona 6-7, 1984-85, pp. 134-137; M. Corsi Sciallano y B. Liou, Archaeonautica 5, 1985.

M. Beltrán Lloris, "El comercio vinario tarraconense en el valle del Ebro. Bases para su conocimiento", Hom. C. Fernández Chicarro, Madrid 1982, pp. 319-329.

${ }_{153}$ A. U. Stylow, Gerión 1, 1983, p. 280 ( $A E$ 1983, n. 535).

154 B. Liou y R. Maréchal, Archaeonautica 2, p. 128, n. 16.

155 Vid. supra: Apartado I.8, Equites, y nn. 92 y 93.

156 F. Mayet, "Les 'figlinae' dans les marques d'amphores Dressel 20 de Bétique», REA 88, 1986, pp. 285-306.

157 E. Rodriguez Almeida y J. Schupbach, Bull. Comn. Archaeol. di Roma 88, 1982-83, pp. 99-103.

158 J. González, Actas Producción y comercio... (supra, n. 18), p. 183 ss. (AE 1984 , n. 526); a propósito de este epigrafe, vid. M. y F. Loyzance, REA 88, 1986 , pp. 273-284.

159 J. González, ibid., p. 190 (AE 1984, n. 528). 
La importante monografia de F. Mayet sobre la sigillata hispanica ${ }^{160}$ contiene una lista de 137 nombres de officinatores; M. Roca ha recogido una serie de inscripciones que no son marcas en la sigillata procedente de Andújar ${ }^{161}$, un centro de producción cerámica estudiado por la escuela de M. Sotomayor ${ }^{162}$. Sobre algunas marcas de la región soriana viene trabajando M. ${ }^{\mathrm{a}} \mathrm{V}$. Romero ${ }^{163}$. Un mapa de la distribución de la marca Sempronius procedente de Tritium Magallum, of rece $\mathbf{M}$. Gasca ${ }^{164}$.

A. Balil ha continuado con su serie de trabajos sobre lucernas ${ }^{165}$; otro foco de atención es el constituido por los lingotes de plomo ${ }^{166}$; es interesante la marca de época republicana $Q$. Sei P.f. Men. Postumi reproducida en 13 piezas nuevas procedentes de Águilas (prov. Mur-

${ }^{160} \mathrm{~F}$. Mayet, Les céramiques sigillées hispaniques: contribution à l'histoire économique de la Péninsule Ihérique sous l'Empire Romain, Paris 1984; rec. M. Sotomayor, Bol. Mus. Arq. Nac. II 2, 1984, pp. 147-150; A. Balil et alii, BSAA 52, 1986, pp. 248262; otras puntualizaciones: M. Roca, Bol. Mus. Arq. Nac. 3,2, 1985, p. 223 ss.

${ }^{161}$ M. Roca, "Inscripciones decorativas en la producción de TSH en los Villares de Andújar", Cuad. Preh. a Univ. Granada 8, 1983, pp. 433-446; las que contienen la fórmula qui me emerit se fechan en época flavia.

${ }^{162}$ Cfr. mi crónica anterior, EMERITA 53, 2, 1985, p. 234, n. 147. Más recientemente: M. Sotomayor et alii, «El centro de producción de cerámica de los Villares (Andújar), campaña 1982», Cuad. Preh. “ Univ. Granada 9, 1984, pp. 235-260; sobre características decorativas de la marca Quartio, procedente de este taller: M. I. Fernández Garcia, Cuad. Preh. ${ }^{a}$ Univ. Granada 10, 1985, pp. 391-411.

Marcas encontradas en Baelo: J. Bonneville et alii, MCV 20, 1984, pp. $477 \mathrm{s.}$

${ }^{163}$ M." V. Romero, "Los vasos firmados M.C.R.", Act. I Symp. de Arq. Soriana, Soria 1984, pp. 341-359 y BSAA 50, 1984, pp. 91-112; eadem, "Los vasos firmados 'Titi Sangeni'», Numantia 2, 1986, pp. 237-246; eadem, "Numancia I", Terra sigillata (Exc. Arq. 146), 1986. Sobre la marca Saturninus, procedente de la misma provincia: C. de la Casa, Hom. Almagro IV. Madrid 1983, p. 53 ss.

Sobre las conservadas en el Museo de Burgos: M. B. Castillo, Numantia 2, 1986, pp. 269-276; sobre algunas procedentes de la provincia de Badajoz; J. Pascual, Rev. Est. Extr. 39, 1, 1983, pp. 135-143. Procedentes de la provincia de Álava: P. Ciprés, Veleia 1, 1984, pp. 193-216.

${ }_{164}$ M. Gasca, Información Arqueológica 44, 1985, pp. 34-37.

Otros trabajos: S. da Ponte, "Nova marca de fabricante en una fibula de tipo Aucissa", Arqueología 16, 1987; J. M. Hidalgo, "Notas arqueológicas en torno al comercio atlántico romano y Vigo", Arqueologia 14, 1986, pp. 113-114; F. J. Fernández Nieto, Symbolae I, pp. 607-611, sobre $A E$ 1976, n. 243: signaculum ocularii.

Otras marcas: L. dos Santos, P. Le Roux y A. Tranoy, Bracara Augusta 83-84, 1983, p. 202 ( $A E A 1983$, nn. 579-580); F. Patricio Curado, $F E 11,1985,46$ b ( $A E$ 1985 , n. 527).

165 A. Balil, BSAA 50, 1984, pp. 190-195; otras marcas, idem, ibid., pp. 176-189; idem, Publ. Inst. Tello Téllez 48, 1983, pp. 299-306.

${ }^{166} \mathrm{Cl}$. Domergue, "L’épigraphie des produits métalliques industriels. L'exemple des lingots de plomb romain d'origine espagnole», Épigraphie Hispanique (supra, n. 2), pp. 199-215; D. Colls, Cl. Domergue y V. Guerrero, "Les lingots de plomb de l'épave romaine Cabrera 5», Archaeonautica 6, 1986, pp. 31-80. 
cia) ${ }^{167}$; en las excavaciones subacuáticas de l'Agadés - entre Ampurias y Marsella - - se han encontrado otros varios, con la siguiente inscripción: Soc. L. Gargili T.f. et M. Laetili M.1. ${ }^{168}$. Unas tuberías de plomo procedentes de $A$ stigi indican que son de propiedad pública ${ }^{169}$; tesserae de plomo con función monetal han sido dadas a conocer por $\mathbf{M}{ }^{\mathrm{a}} \mathbf{P}$. García y Bellido ${ }^{170} ; \mathrm{J}$. Lancha ha recogido las firmas que se encuentran en los mosaicos de la Península ${ }^{171}$.

\section{Inscripciones cristianas y de época visigoda}

Marcos Pous ha publicado una serie de 28 piezas --moldes de ladrillo - cordobesas con la fórmula Saluo Ausentio; su cronología va de finales del s. IV a comienzos del VII ${ }^{172}$. A propósito de Vives 5802, Cugusi estudia algunos "dobletes» en epigrafes métricos ${ }^{173}$; una inscripción dificilmente interpretable figura en una patena visigótica del Museo de Lugo ${ }^{174}$. Unas notas de J. Gil completan y rectifican la lectura hasta ahora dada a la pizarra visigótica de Carrio que se conserva en la Academia de la Historia: contiene una copia retocada de un pasaje de la passio de S. Cristóbal ${ }^{175}$.

${ }^{167}$ Cl. Domergue y J. Mas, XVI CAN, Zaragoza 1983, pp. 905-909; ibid., una incompleta ( $A E$ 1983, nn. 604-605).

${ }_{168}$ D. Fonquerle, Ampurias 44, 1982, pp. 121-131.

169 G. Chic y M. ${ }^{a}$ E. Martínez Ortega, Gades 12, 1984, p. 386: C(olonorum) C(oloniae) Aug(ustae) Fir(mae) ex offi(cina) Murcari.

${ }^{170} \mathrm{M}{ }^{\mathrm{a}} \mathrm{P}$. García y Bellido, "Nuevos documentos sobre minería y agricultura romanas en Hispania", AEArq. 59, 1986, pp. 13-46: contiene nuevo material numismático y tesserae con marcas procedentes de distritos mineros y fechables entre fines de la República y comienzos del Imperio. Anuncia la próxima aparición de un Catálogo de plomos monetiformes de la Hispania antigua.

171 J. Lancha, $M C V$ 20, 1984, pp. 45-61: propone nueva lectura del mosaico de Océano de Faro. En Andión (provincia Navarra) ha aparecido recientemente un mosaico de Baco con la firma... on $f:$ M." A. Mezquiriz: Tr. de Arq. 5, 1986, pp. $237-$ 249.

172 A. Marcos Pous, Corduba Archaeologica 11, 1981, pp. 47-68.

${ }_{173}$ P. Cugusi, Ann. Cagliari n. s. 3, 1980-81, pp. 11-19.

174 N. Ares, Bol. Mus. Prov. Lugo 1, 1983, pp. 209-211. Otros epigrafes visigóticos: M. Mayer e I. Rodá, Fonaments 5, 1984, p. 179 (funeraria de Tarragona); C. Sáez Sánchez, An. Est. Med. 15, 1985, pp. 35-38 (10 pizarras con cifras incisas, de significado desconocido); J. H. Ruiz y M. Urteaga, Arch. Leon. 81-82, 1987, pp. 301310 (lápida funeraria en lengua muy vulgar); R. Bohigas, Altamira 43, 1981-83, pp. 347-349.

175 J. Gil, Habis 12, 1981, pp. 153-176. Este artículo misceláneo contiene además una inscripción emeritense de época visigoda; dos griegas tardias; dos mozárabes conservadas en el MAN y procedentes de Córdoba y varias inscripciones falsas inventadas por Trigueros.

Otras noticias de inscripciones cristianas y visigodas: G. Fabre, M. Mayer e I. 
Algunas inscripciones cristianas figuran en catálogos locales o de regiones ${ }^{176}$; una publicación aparte han merecido las placas decoradas con inscripción, que se conservan en el Museo Arqueológico de Sevi$1 \mathrm{lla}{ }^{177}$; en esta provincia, y procedentes del yacimiento de La Cañada, se han encontrado tres nuevas de época visigótica ${ }^{178}$.

Una curiosa placa de mármol blanco - decorada con la representación de fachada, frontón y columnas de un pequeño templo - se conserva en el Museo de Mérida desde 1980; en ella se lee: Et ante luna sedis eius: debajo, un creciente lunar; Blanco la fecha entre los s. vi y vII, y la atribuye a una secta filosófica no identificable ${ }^{179}$. Debe notarse que el texto, con grafia vulgar (la forma clásica sería et ante lunam sedes eius) presenta cierta coincidencia con una frase de Plinio referida al cielo: infra lunam haec sedes (NH II 102); pero más sugestiva resulta su semejanza con algunos versículos de los Salmos ${ }^{180}$. Esta semejanza y el carácter métrico del texto (un dímetro yámbico) me hacen pensar que lo que aquí se reproduce es un verso de un himno litúrgico de factura ambrosiana.

Por otra parte, en Mértola se ha encontrado una menorah de la liturgia judaica fechada en el a. 482: es la más antigua de este tipo conocida en la Península ${ }^{181}$.

Rodá, Ampurias 44, 1982, pp. 185-240 ( $A E$ 1983, n. 618); M. Mayer e I. Rodá, Fonaments 5, 1984, p. 179 (AE 1985, n. 632); A. U. Stylow, Bol. de Inf. Municipal de Montilla 54-55, 1985, pp. 36-38 ( $A E$ 1985, n. 558); M. ${ }^{a}$ M. Alves Días y C. Torres, $F E$ 9, 1984, nn. 35-39 ( $A E 1985$, nn. 505-509): se indica que se conocen casi 40 epígrafes cristianos en Mértola, datados entre los a. 470 y 706.

176 M. Mayer e I. Rodá, Fonaments 6, 1985, pp. 193-21: un sello de bronce con la leyenda Geront( $i$ ) / uiuas (i)n (pace), junto a otros dos semejantes ya conocidos; nueva lectura de RIT 965, detable en el s. v; M. Almagro Basch, Segobriga II: 6 cristianas ya conocidas; M. A. Rabanal y J. M. Abascal, Lucentum 4, 1985, p. 200, n. 19 (AEA 1986, n. 438); F. Beltrán, Annales 4, 1987, p. 19 ss.: conjunto de Coscojuela.

177 C. Martín Gómez, Museos 1, 1982, pp. $37-43$ ( $A E$ 1986, nn. 326-331): es un inventario del material ya conocido por Vives. Una inscripción visigótica en una placa del Museo de Santa Cruz de Toledo: G Alföldy, Studi tardoantichi II, 1986, pp. 117-184; cf. S. Cortés et alii, Museos 3, 1984, p. 78, n. 8.

178 J. González, Epigrafia del yacimiento de La Cañada. Estudios sobre la Tabula Siarensis (supra, n. 19), nn. 19-21.

Nuevas lecturas de epigrafes ya conocidos: A. Rodríguez Colmenero, $\mathrm{Mem} . \mathrm{H}^{a}$ Ant. 8, 1987, pp. 177-186; S. Mariner, Bivium (Hom. Diaz y Diaz), Madrid, pp. 167173: sobre $R I T 955$ y 1003 .

179 A. Blanco Freijeiro, $B R A H 180,2,1983$, p. 240 ( $A E 1983$, n. 488).

${ }_{180}$ Et thronus eius sicut sol... et sicut luna perfecta in aeternum (Ps. 88, 38); et permanebit cum sole et ante lunam generationes generationum (Ps. 71, 5); ante solem permanet nomen eius (Ps. 71, 17).

181 M. ${ }^{2}$ M. Alves Días, $F E$ 21, 1987, n. 93: cita como paralelo Vives, ICERV 430. Ibid., nn. 94-97: cristianas. 


\section{INSCRIPCIONES AGRUPADAS GEOGRÁFICAMENTE}

\section{Lusitania}

Aqua Augusta se lee en una piedra que formaba parte del acueducto meridional de Emerita: el más antiguo de los tres que conducían el agua a la capital de Lusitania ${ }^{182}$. Varios epígrafes emeritenses ha publicado García Iglesias ${ }^{183}$; uno de ellos, puesto a la Domina curatrix animae, un apelativo que se encuentra también en Italica y que se refiere, al parecer, a Némesis ${ }^{184}$. De las inscripciones emeritenses conservadas en Barcelona dan cuenta Fabre, Mayer y Rodá ${ }^{185}$. Varios autores aportan novedades al catálogo epigráfico de Cáceres ${ }^{186}$.

Como ya hemos dicho más arriba, disponemos ahora de un corpus que contiene las inscripciones del Conuentus Pacensis ${ }^{187}$. J. d'Encar-

182 J. Hiernard y J. M. Ảlvarez Martínez, Sautuola 3, 1982, pp. 221-229.

${ }_{183}$ L. Garcia Iglesias, Rev. Est. Extr. 39,3, 1983, pp. 577-590 (AE 1983, nn. 489494): 3 funerarias inéditas y 2 correcciones de lectura: CIL II 577 e ILER 3669; EE VIII 63 es falsa. Idem, ibid., 40,1, 1984, pp. 145-159 ( $A E$ 1984, nn. 485-489): 3 inéditas y otras revisadas. La que corresponde al n. 485 de $A E$ es una dedicatoria al genio de la Colonia, puesta por un liberto; el mismo texto, con alguna variante, en $\mathbf{R}$. Étienne y F. Mayet, Lucerna (Hom. Pinho Brandão), Porto 1984, p.168.

184 Ibid., p. 151 ( $A E$ 1984, n. 486); el texto de Italica es una nueva lectura de $A E$ 1908, n. 151, ofrecida por A. M. Canto, $Z P E$ 54, 1984, p. 185 ( $A E$ 1984, n. 505).

185 Ampurias 44, 1982, pp. 982, pp. 185-242: 9 emeritenses y 4 de otros lugares de Lusitania; las inéditas en $A E$ 1983, nn. 614-619.

186 L. Téllez, I. Rosco y J. Riomiranda, Bol. Inf. Grupo Cultural Valdeobispo 7, Marzo 1982, pp. 6-15: continúa el inventario iniciado en el n. 6 de esta publicación; J. L. Sánchez Abal y J. Salas Martín, Norba 4, 1983, pp. 263-276: 6 inéditas ( $A E$ 1983, nn. 498-500); J. J. Sayas y J. L. Sánchez Abal, Norba 2, 1982, pp. 165-173; M. J. de Torres, Hom. Almagro III, Madrid 1983, pp. 365-369: 2 inéditas ( $A E$ 1983, nn. 501-502).

Otras aportaciones a la epigrafia de Extremadura: F. Hernández, Nuevos grafitos de Extremadura, NAHisp. 20, 1985, pp. 219-224; J. Salas, Veleia 4, 1987, pp. $127-$ 143; J. A. Redondo, Vettonia 1, 1983, pp. 37-48: 6 funerarias con lecturas poco seguras y una ara a Júpiter; S. G. Armstead, AEArq. 58, 1985, pp. 155-158 (AE 1985, nn. 535-538).

${ }_{187}$ Cf. supra, n. 24. Las inéditas, en $A E$ 1984, nn. 459-464. El catálogo recoge las publicadas en $F E$ hasta el n. 6, 1983, inclusive. M. J. Rinbeiro Marcial, $F E$ 15, 1985 , n. 64 trata de IRCPac. n. 485 con diferente lectura $(A E 1985$, n. 503); M. C. Lopes, Conimbriga 25, 1986, pp. 205-212, da IRCPac. 333a; el fragmento de Alcacer do Sal publicado por J. C. Lázaro, $F E 9,1984$, n. $40(A E 1985$, n. 499) estaba ya recogido en IRCPac. n. 188; a este mismo personaje Cornelius Bocchus se refiere seguramente el fragm. n. $41(A E 1985$, n. 500); también está en IRCPac., n. 460, la publicada por M. ${ }^{a}$ M. Alves Días, $F E$ 16, 1986, n. 73; $A E$ 1986, n. 281.

Otras más recientes del mismo conventus: M. J. Pinheiro Maciel, FE 1.5, 1985, nn. 65-66 ( $A E$ 1985, nn. 501-502): esta última da un nuevo testimonio del nombre Helpis que hemos leído en dos epígrafes navarros (cf. IRMNa., nn. 30-31); J. Pascual, FE 12,1985 , n. $50(A E 1985$, n. 534). 
nação da noticia de lo que parece una primera mención de un nuevo gentilicio: Segaius ${ }^{188}$.

Siguen siendo frecuentes las noticias de dedicatorias a Júpiter Óptimo Máximo ${ }^{189}$; más raramente con otros epítetos ${ }^{190}$. Una dedicatoria deae ha suscitado polémica acerca de su atribución ${ }^{191}$.

En el catálogo de inscripciones de Salama, elaborado por J. L. Melena, hay una nueva lectura de un epigrafe dedicado a una divinidad con este nombre: Fuscus deo o(ptimo) / Salamati / u.s.l.m. ${ }^{192}$.

Un ara a la que falta el nombre de la divinidad está dedicada por un ...us Flacci (f.) Cobelcus ${ }^{193}$; Cobelcus aparece abreviado en CIL II

${ }^{18 *}$ J. d'Encarnação, Arq. de Beja 30, 1986, pp. 133-140. Hay un Sagatius documentado en la Galia Cisalpina (cf. A. Moçsy, Nomenclator Provinciarum Europae, Budapest 1983, p. 250); J. d'Encarnação publica la misma inscripción en $F E 18$, 1985 , n. 82 ( $A E$ 1986, n. 280).

${ }_{189}$ F. Patricio Curado, FE 11, 1985, n. 45 (dedicado por los uicani Goaboic(enses); idem, ibid. 17, 1986, n. $75(A E 1986$, n. 300), muy cuidada, de tipo monumental; M. Leitão, Revv. Guimaraes 95, 1985, pp. 159-163; L. F. C. Gomes, FE 16, 1986. n. 69 ( $A E$ 1986, n. 295); M. M. Alves Dias, $F E 20,1986$, n. 90.

190 J. d'Encarnação y F. Geraldes, Conimbriga 21, 1982, pp. 135-142 (AE 1982. n. 473): sup(remus) su(m)mus; vid. supra, n. 13.

191 J. d'Encarnação, $F E$ 6, 1983, n. 24 ( $A E$ 1983, n. 470); J. Alvar, AEArq. 56, 1983, pp. 123-130 ( $A E 1984$, n. 476) la atribuye a Cibeles; vid. la contestación de Encarnação en Actas IV LCP (supra, n. 18), pp. 305-310; J. M. Alvarez Martínez, Bol. Mus. Zaragoza 4, 1985, pp. 167-173: una atribuida a Ataecina; anuncia un corpus de dedicatorias a esta divinidad en el S.O. de la Península. También está dedicado deae sanctae un epígrafe de Serpa: M. ${ }^{\star}$ M. Alves Días y A. M. Monge Soares, $F E 18,1986$, n. 84 ( $A E$ 1986, n. 278 , que corrige la lectura de la 2 . $^{a}$ lín. $) ; \mathrm{M} .{ }^{a} \mathrm{M}$. Alves Días, ibid., 5, 1983, n. 16: Fonti. De dificil interpretación son las siglas M.B.S. que figuran en otra votiva, dedicada por Iulia Firmina: F. Patricio Curado, FE 17 , 1986, n. 76 ( $A E 1986$, n. 297). teónimos.

192 Vid. supra, n. 130, donde se relacionan los epigrafes que documentan nuevos

Otras dedicatorias a divinidades indígenas: F. Patricio Curado, $F E 7,1984$, n. 26 , de lectura dudosa ( $A E$ 1984, n. 478); idem, ibid., n. 28 ( $A E$ 1984, n. 480; idem, $F E$ 13,1985 , n. $57(A E 1985$, n. 531); idem, $F E 17,1986$, n. $74(A E 1986$, n. 301): poco comprensible, quizá reinscrita; idem. $F E 22,1987$, n. 98 , dedicada por los Berecenses: el A. la relaciona con A. González Cordero et alii, Studia Zamorensia 6, 1985, pp. 277-300, n. 2: Q. Dobiteri f. Berc(ensis); idem, FE 22, 1987, nn. 99-100; J. d'Encarnação, $F E$ 14, 1985, n. 59; M. Figuerola, $F E$ 12, 1985, n. 49 ( $A E$ 1985, n. 539); L. F. C. Gomes y A. M. M. Tavares, $F E 13,1985$, nn. $54-55$ ( $A E$ 1985, nn. 516517).

Sobre las divinidades acuáticas en territorio olisiponense: J. Cardim Ribeiro, Bol. Cult. de Assamblea distr. de Lisboa 89,1, 1983, pp. 3-41.

${ }^{193}$ F. Patricio Curado, $F E 11,1985$, n. $46(A E$ 1985, n. 526).

Otras dedicatorias en las que falta total o parcialmente el nombre de la divinidad: F. Patricio Curado, $F E$ 17, 1986, n. 77 ( $A E$ 1986, n. 299); idem, ibid., n. 78 ( $A E$ 1986, n. 303); M. L. Lopes Tomé, $F E$ 5, 1983, n. 17; M. Leitão, ibid., n. 76 ( $A E$ 1985, n. 529); R. Carvalho, FE 23, 1987, nn. 104-105. 
433, del que tenemos ahora nueva lectura ${ }^{194}$. Hay en Emerita un epígrafe cuya existencia ha pasado inadvertida ${ }^{195}$, que nos da el mismo nombre: Cobelcus; el lugar que ocupa este elemento en la fórmula onomástica y el sufijo -cus hacen pensar que estamos ante la mención de una gentilidad.

Sobre CIL II 5264, dedicatoria puesta a Tito por la provincia de Lusitania, escribe Fishwick ${ }^{196}$.

Un monumento funerario de tipo poco común han presentado J. Beleza y J. d'Encarnação al Primer Congreso Peninsular de Historia Antigua ${ }^{197}$. En una sepultura familiar aparece la forma Celtiatis, variante de Celtius ${ }^{198}$; la inscripción funeraria de L. Cornelius Mitulus puede fecharse en el s. I a. C. ${ }^{199}$; otra, procedente de Nisa, da un nuevo nombre: $T u$ lorus $^{2(x)}$.

De una zona imprecisa de Extremadura procede un epígrafe conservado en el Museo Marés de Barcelona ${ }^{201}$.

Una buena parte del material que venimos anotando se ha publicado en Ficheiro Epigráfico, en cuyo fascículo núm. 10, correspondiente a

${ }^{114}$ Modestus Auiratif. Cohel(cus) an. LX...: lectura de Martín Valls, reproducida por Patricio Curado, l.c. en n. 193.

145 A. Holgado, Anuario de Estudios Filológicos 3, 1980, pp. 89-96: D.M.S. I Martialis Oclati f. / Cohelcus, ann. XXXVI/ h.s.e. s. I. t. I. / Petreia Marcella uxor fecit.

196 D. Fishwick, Amer. Journ. of Anc. Hist. 6, 1981, pp. 89-96 (AE 1982, n. 486).

147 J. Beleza y J. d'Encarnação, Actas ( $P H A$ (cf. supra, n. 22), pp. 5-9. Es el mismo epigrafe publicado en $F E 18,1986$, n. 81 ( $A E$ 1986, n. 282), con un final de dificil interpretación. Otras funerarias publicadas por estos autores: J. Beleza. Conimbriga 21, 1982, pp. 143-149 ( $A E$ 1982, n. 471); J. d'Encarnação, $F E$ 10, 1984, n. 43 ( $A E$ 1985, n. 51); J. d'Encarnação y R. Carvalho, Belver ao tempo dos Romanos, Portalegre 1985 ( $A E$ 1984, nn. 470-474); J. Cardoso y J. d'Encarnação, $F E$ 14, 1985, n. 68 ( $A E$ 1985, n. 513); J. d'Encarnaçào, $F E$ 25, 1987, nn. 116-117.

${ }_{198}$ F. Patricio Curado, $F E$ 22, 1987, n. 101. Otras funerarias publicadas por el mismo autor en $F E$ 8, 1984, nn. 30-31 ( $A E$ 1984, nn. 482-483); 11, 1985, n. 47 ( $A E$ 1985$, n. 528$) ; 14,1985$, n. $62(A E 1985$, n. 522$) ; 13,1985$, n. $58(A E 1985$, n. 532$)$; 17, 1986, n. 79 ( $A E$ 1986, nn. 302-303).

${ }_{194}$ M." M. Alves Dias, $F E$ 18, 1986, n. 83 ( $A E$ 1986, n. 279). Otras funerarias publicadas por la misma autora: Euphrosyne 12, 1983-84, pp. 235-238; O Arq. Port., ser. IV 1. 1983, pp. 323-336 (estudio onomástico); $F E$ 20, 1986, n. 91 ( $A E$ 1986, n. 277): $F E$ 21, 1987, n. 92: estas dos últimas datables en el s. III.

200 A. E. Maia do Amaral, FE 23, 1987, n. 107.

Otras lápidas funerarias de Lusitania: M. Leitão y L. Barata, Trahalhos de Antr. (Etnol. 23,4, 1980, pp. 627-634 ( $A E$ 1982, nn. 475-477); R. Martín Valls, Zephyrus 34-35, 1982, pp. 181-191 ( $A E$ 1983, nn. 504-52): nótese que en la 508 figura Arqui, Gen. de Arquius, y en la 511 Arconis, gen. del indigena $\operatorname{Arc}(O)$ idem, ibid., pp. 213-250 $(A E 1983$, n. 503); V. G. Mantas, Conimbriga 24, 1985, pp. 125-149 ( $A E$ 1985, nn. 510-512); J. O. Caeiro, Arqueologia 11, 1985, p. 120 ( $A E$ 1985, n. 504), donde se insinúa que puede tratarse del inicio de un carmen.

201 G. Fabre, M. Mayer e I. Rodá, Ampurias 44, 1982, p. 208, n. 16 ( $A E 1983$, n. 613); según los editores de $A E$ puede tratarse de una copia. 
1984, hay una relación de addenda y corrigenda y unos índices de los primeros fascículos (un total de 43 inscripciones) ${ }^{202}$.

V. G. Mantas reúne trece inscripciones procedentes de Torres Vedras ${ }^{203}$; un catálogo de 15 textos, entre ellos 5 inéditos, presenta J. L. Inés $\mathrm{Vaz}^{204}$. Otros conjuntos aparecen ordenados según el Museo en que se conservan ${ }^{205}$. J. d'Encarnação aborda el tema general de romanización e indigenismo en Lusitania, considerando tres aspectos: a) religión; b) antroponimia; c) tipología de los monumentos ${ }^{206}$.

\section{Bética}

Se ha constatado la existencia de un segundo foro en Hispalis, interpretado como foro de las corporaciones, similar al existente en el puer-

202 Otras de carácter funerario publicadas en $F E: 5,1983$, n. 19; 8, 1984, n. 34 ( $A E$ 1984, n. 477); 12, 1985, n. 51 ( $A E$ 1985, n. 533); ibid., nn. 52-53 ( $A E$ 1985, nn. 519-520): lectura mejorada de 520 en $F E$ 20, 1986, add. et corr.; 13, 1985, n. 56 ( $A E$ 1985 , n. 518); 14, 1985, n. 60 ( $A E 1985$, n. 530); ibid., n. $61(A E 1985$, n. 521); 24, 1987, nn. 108-112; 25, 1987, n. 113. Un cipo de dificil lectura e interpretación en 7 , 1984, n. 29 ( $A E$ 1984, n. 483).

${ }^{203}$ V. G. Mantas, Conimbriga 21, 1982, pp. 5-99 ( $A E$ 1982, nn. 463-470): algunas de ellas ya incluidas en $C I L$ II; en $A E$ se introducen correcciones a las lecturas; idem, Orarium donauit Igaeditanis, Actas CPHA (supra, n. 22), pp. 415-440: sobre ILER 2082; idem, "A inscrição rupestre da estação luso-romana de Mogueira ( $\mathrm{Re}-$ sende)", Rev. Guimarães 94, 1984, pp. 361-370 (AE 1986, n. 293), donde se hace notar la dificultad de la lectura.

Otras nuevas lecturas: A. E. Maia do Amaral, Conimbriga 21, 1982, pp. 101-126: sobre CIL II 396, 397, 5245; L. A. Curchin, «Epigraphic Notes from the spanish Meseta", ZPE 58, 1985, pp. 244-246 ( $A E$ 1985, nn. 543-546); J. M. Abascal, In mem. A. Diaz Toledo, Granada 1985, pp. 31-34 (AE 1985, n. 535): sobre CIL II 696; A. Rodriguez Colmenero, Arqueología 12, 1985, pp. 195-201: sobre CIL II 2476; J. d'Encarnação y M. Leitão, Conimbriga 21, 1982, pp. 127-133 ( $A E$ 1982, n. 474); J. Lancha, $M C V 20,1984$, p. 59 ss. y Conimbriga 24, 1985, p. 173: vuelve sobre $A E$ 1981 , n. 490 ( $A E 1984$, n. 457).

204 J. L. Ines Vaz, Beira Alta 41,3, 1982, pp. 3-30 (AE 1983, nn. 478-485, ccn correcciones de lectura y otras indicaciones); idem, "Lápida romana de Mejinhos", Beira Alta 42, 1983, pp. 577-581. El primer vol. de la revista Trebaruna (1981) contiene varias contribuciones referidas a diferentes regiones portuguesas.

$205 \mathrm{~J}$. Mendes de Almeida, "Las inscripciones griegas del Museo Nacional», $\mathrm{Ar}$ queologia 13, 1986, pp. 173-180: 6 inscripciones, tres de ellas inéditas; idem, "A epigrafia na exposição de escultura romana de M.N.A.E.", O Arq. Port. ser. IV 1, 1983, pp. 337-346; M. M. Alves Días, «Inscripciones procedentes de Carquera (Resende) en el M.N.A.E. de Belem", $O$ Arq. Port. IV 4, 1986, pp. 187-202 ( $A E$ 1986, nn. 284-292).

206 J. d’Encarnação, Biblos 62, 1986, pp. 451-464. Él mismo hace la historia de los estudios epigráficos en Portugal desde el s. xvı hasta nuestros días en Arqueologia 17, 1988, pp. 204-207 (conferencia celebrada en junio de 1985). 
to de Ostia ${ }^{207}$; en él se encuentran: una inscripción votiva puesta por los [uina]ri Romulae consistentes a Liber Pater; una monumental de Antonino Pío, que parece contener la autorización para la constitución de un collegium centonariorum, y una dedicatoria imperial fechada entre los a. $209 / 212$.

El yacimiento de La Cañada ha dado, entre otras novedades, una dedicatoria a Pertinax, del a. $193^{208}$. En Olvera (Cádiz) se ha encontrado una dedicatoria a Trajano: es un pedestal espléndidamente decorado ${ }^{209}$, que por otra parte asegura la existencia y la localización de la ciudad de Saepo en el conuentus Hispalensis, como ya había visto Tovar ${ }^{210}$.

Posterior a la redacción del corpus epigráfico italicense es la noticia sobre L. Herius, notable local que gozó de la duouiralis potestas por tercera vez antes de ser nombrado pontifex primus Augusto, e hizo una importante donación al municipio ${ }^{211}$. En época posterior, cuando ya Italic $a$ era colonia, otro personaje notable hace una importante of renda con motivo de su designación como augur perpetuus; con anterioridad había sido edil y duouir ${ }^{212}$. Otra donación cuantiosa es la que hace, ob honorem Iluir(atus), M. Cassius, Serg., Caecilianus, que fue en la colonia Flamen perpetuus diui Traiani, antes de ocupar el flaminato provincial $^{213}$. En un epígrafe dado a conocer en 1986, figura un $M$. Trahius, que podría ser el más antiguo antepasado de Trajano del que tenemos

207 J. Campos y J. González, AEArq. 60, 1987, pp. 123-158. Con motivo del hallazgo de un ara funeraria en Sevilla, A. Caballos y M. M. Ruiz Delgado, Habis 15, 1984, pp. 257-274: estudio de los formularios hispalenses; son consideraciones que no representan grandes novedades; tampoco el número de inscripciones sobre el que trabajan 57 permite conclusiones muy seguras. La lectura del ara, corregida por J. Gil, Habis 16, 1985, p. 185, n. 4: linn. 6-7, Petronius F. Pacatianus debe leerse Epacatianus.

${ }_{20}$ J. González, «Epigrafia del yacimiento de La Cañada, Estudios sobre la Tabula Siarensis (supra, n. 19), pp. 91-126. Contiene un total de 34 epigrafes, 15 de ellos inéditos.

${ }^{209}$ Cf. supra, n. 72.

${ }^{210}$ Cf. Iberische Landeskunde II, Bd. I: Baetica, p. 61. Cf. supra, apartado I.6 con n. 72 .

211 Cf. supra, apartado 1.10: Flamines y Pontifices, con n. 117.

212 Cf. supra, n. 120. El personaje M. Sentius M.f. Serg. Maurianus no figura en el catálogo de tribus elaborado por Wiegels; seguramente era pariente de $M$. Sentius Restitutus, duouir de Oha (CIL II 1330; PB 291), contemporáneo suyo.

${ }_{213}$ Vid. supra, apartado I.10, Flamines y Pontifices, con n. 115. Acerca de su posible identificación con un Caecilianus de otro epígrafe italicense, vid. supra, Flamines y Pontifices, con n. 116. Es probable que pertenezca a la misma familia que $M$. Cassius Agrippa, del orden ecuestre, honrado en Córdoba (CIL II 2212; PIR II p. $112, \mathrm{n}, 482 ; P B 89)$. Más arriesgado es por el momento establecer relación con ('assius Faustus (CIL VI 1625 b; PB 90), negotiator olearius de la Bética. 
noticia ${ }^{214}$. Tampoco lleva cognomen el italicense al que iba dedicado un pedestal puesto por su hija ${ }^{215}$. A. M. ${ }^{\text {a }}$ Canto propone nuevas lecturas de inscripciones votivas con plantae pedum procedentes del anfiteatro de Italica $^{216}$.

En Carissa Aurelia (Bornos, Cádiz) se ha encontrado una dedicatoria a Tiberio ${ }^{217}$; otra, a Tito, fue puesta por la respublica Reginensis ${ }^{218}$.

Un número elevado de epigrafes correspondientes a la provincia de Córdoba ha sido publicado, o en otros casos reeditado con nuevas lecturas, por parte de A. U. Stylow ${ }^{219}$. Una de ellas está dedicada a un duouir del que sólo queda el cognomen -Crassus - que no coincide con el de ninguno de los hasta ahora conocidos; la paleografia y la estructura del texto aconsejan fecharlo entre los a. $80 / 120$ d. C. ${ }^{220}$; en

214 Vid. supra, n. 38.

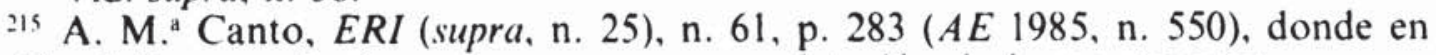
función de la ausencia de cognomen se propone datación de época augustea.

216 A. M. Canto, ZPE 54, 1984, pp. 183-194, ( $A E$ 1984, nn. 501-506); en n. 7 ( $A E$ 505): Lucanus Fedeles / Domin(a) e cur(atrici) ani/mae, interpretado como dedicatoria a Némesis; en $A E$ se plantea la pregunta de si se trata de Lucanus (esclavo de) Fidelis o de dos dedicantes, pero es posible que Fidelis no sea aquí un nombre propio sino el adjetivo fidelis al que sigue, en Dativo, el nombre de la divinidad.

Las inscripciones funerarias de Italica publicadas en Habis 9, 1978, pp. 197-202. son falsas, según averiguaciones hechas posteriormente, vid. J. A. Correa y J. González, Habis 12, 1981, pp. 147-151.

Acerca de un ara votiva de Italica ya conocida, J. Beltrán Fortes, Baetica 7. 1984, pp. 113-118, interpreta las siglas L.T.B. como iniciales del dedicante; en este mismo sentido, A. M. Canto, ERI (supra, n. 25), n. 19, p. 157. En p. 115, n. 7, se da noticia de un ara inédita piocedente de Nescania: I.D. / L.C.E. / D.D.D.

217 P. Rodríguez Oliva y J. Beltrán Fortes, Baetica 9, 1986, pp. 219-226: la ponen en relación con CIL II 1367. Sobre esta misma inscripción: P. Rodríguez. Oliva, R. Atencia y J. Beltrán, Mainake 8-9, 1986-87, pp. 249-251, y Dos nuevos testimonios héticos sobre Tiherius Caesar, Málaga 1986, pp. 27-32. G. Alföldy, ZPE 59, 1985. pp. 188-199 trata de CIL II 1660, Tucci: dedicatoria a Hércules hecha por Tiberio, en la que seguramente falta el nombre y cargo de quien puso el monumento, que debió de ser un gobernador; en $A E$ 1985, n. 555 se insinúa la posibilidad de que fuera un procurator del Emperador.

J. Beltrán F., Baetica 9, 1986, pp. 191-203, interpreta CIL II 951 como ara de culto a Augusto; idem, Mainake 45, 1982-83, pp. 227-236: sobre (IL II 2011; idem, ibid., pp. 237-242 (AE 1985, n. 380): dedicatoria a los lares uiales seguramente puesta por el mismo personaje que dedicó CIL. Il 2062 a Tiberio.

218 J. M. Álvarez Martinez, "Epigrafia reginense», Museos 1, 1982, pp. 9-15, n. 2: hay 4 inéditas, aunque en $A E 1986, n$. 324 se dice que el A. solamente reedita y comenta. Idem, Bol. Mus. Zaragoza, 1985, pp. 167-174: nuevo epigrafe reginense, dedicado Genio oppidi, con lectura incompleta.

219 Además de los citados supra, n. 26: Gerión 1, 1983, pp. 267-303 (AE 1983, nn. 533-541); Gerión 3, 1985, pp. 317-346 (AE.1985, nn. 560)-569); Gerion 4, 1986, pp. 285-311; Faventia 8, 1, 1986, pp. 78-95; Actas XVII CNA, Zaragoza 1985, pp. 657666.

220 Idem, Gerión 3, 1985, pp. 333-337, n. 6 ( $A E$ 1985, n. 565).

C. Puerta, ibid., pp. 337-346: 3 funerarias incompletas ( $A E$ : 1985, nn. 566-568), y un fragmento de lectura insegura $(A E$ 1985, n. 569). 
otro hallazgo hecho en Córdoba, se encuentra el primer testimonio epigráfico de la existencia de un acueducto en la capital de la Bética: Aqua Noua / [[Domitiana]] / Aug(usta); quizá el Emperador, cuyo nombre se borró después, participó en su día en los gastos de esta obra pública ${ }^{221}$; a la época de Vespasiano corresponde un nuevo terminus inter Lacinimurg(enses) et Vccubitanos c(olonos) C(oloniae) Claritatis Iuliae ${ }^{222}$; en Vlia se ha encontrado una dedicatoria en la que se honra a $L$. Caesar como patrono de la ciudad ${ }^{223}$. Un liberto que ejercía el oficio de dissignator, ha aparecido también en Córdoba ${ }^{224}$.

Varios autores han realizado un estudio de conjunto sobre los retratos hermaicos con dedicatoria 225 .

En una inscripción reciente de Astigi (Écija) se lee: Aponia C:f. Montana, nomine Caesi Montani fili sui, ex a[rg.] / libris C, testamento suo poni iussit. Heredes non ded(uxerunt) ${ }^{226}$. Aponia es seguramente la sacerd. diuar. Augustar. col. Aug. Fir. (CIL II 1471), que dispuso la celebración de juegos circenses ob honorem sacerdotii; la nueva inscripción nos da el nombre de su marido Caesius; resulta tentador pensar que pudo ser $Q$. Caesius Caesianus, mercator de aceite que figura en ánforas

221 A. U. Stylow, Gerion 4, 1986, pp. 285-289 ( $A E$ 1986, n. 335).

222 Idem, ibid., pp. 307-311; anteriormente editado por D. Vaquerizo, Rev. Est. Extr. 42, 1, 1986, p. 115 ss., con algunas variantes de lectura el artículo recoge otras 13 piezas; la que aquí nos ocupa habia sido publicada por J. Alvarez Sáez de Buruaga en Augusta Emerita, Act. Symp. Int. conmemorativo del himilenario de Merida, Mérida 1975-76, p. 23, n. 31, con lectura incompleta.

Otros epigrafes de la provincia de Badajoz: A. Garcia Galán, Re'v. Est. Exvrr. 40, 2, 1984, pp. 355-357; D. Vaquerizo, RA Madrid 70, 1987, pp. 29-34.

223 A. U. Stylow, Faventia 8, 1, 1986, p. 78 ss., n. $6(A E$ 1986, n. 374); el editor hace notar que no se trata de la recuperación de ('IL II 1526. Es cosa conocida la lealtad de Vlia a la familia de César; acerca de un epigrafe de época republicana procedente de las cercanias de esta ciudad, vid. supra, n. 36.

224 A. M. Vicent y A. Marcos Pous, Corduba Archaeologica 15, 1984-85, pp. 6566. Otros epigrafes de Córdoba y provincia: J. Serrano y J. A. Morena, Arqueología inédita de Córdoha y Jaén, Córdoba 1984; J. M. Iglesias, FE 19, 1986, nn. 85-88 (AE 1986, n. 336); C. Fernández Ochoa e't alii, Cuad. de Prch.“ y' Arqueologia 9-10, 198283, pp. 211-220: un fragmento con el epigrafe [S]isapon[nensium?] que induce a considerar la posibilidad de que Sisapo no se localice en Almaden; J. F. Rodriguez Neila. Hahis 14, 1983, pp. 174-192: 2 funerarias inéditas.

En la provincia de Jaén: M. Pastor, Hom. Saénz de Buruaga, Madrid 1982, pp. 351-357: 2 funerarias inéditas ( $4 E 1982, \mathrm{nn}$. 625-626, con correcciones de lectura).

"2s R. Portillo, P. Rodriguez y A. U. Stylow, $M M$ 26, 1985, pp. 185-217, of. supra, n. 30 .

Otros trabajos sobre hermae: P. Rodriguez Oliva, Baetica 5, 1982, pp. 133-141; idem, Baetica 8, 1985, pp. 165-190 y Not. Ary. Hisp. 25, 1985, p. 363.

${ }^{226} \mathrm{~S}$. Ordóñez, Act. I Congr. H." de Écija, Écija 1986, reproducida por G. Chic, Hahis 18-19, 1987-88, p. 366 ss.

Sobre ('IL. II 1180 y 1183 , vid. S. I)ardaine y H. Pavis d'Escurac, Klema 8, 1983, pp. $307-315$. 
con control en Astigi en el a. 149, o bien su socio Q. Caesius Macrinus (cf. CIL XV 3797-99).

Algunos epígrafes atribuidos por Hübner a Anticaria proceden seguramente de Nescania ${ }^{227}$. En Baelo se han encontrado dos dedicatorias a Isis, fechables en el s. II ${ }^{228}$. Son varios los epígrafes béticos conservados en Cataluña ${ }^{229}$.

J. Gil ha vuelto sobre la lectura de la tegula de Villafranca de los Barros: rechaza la propuesta de Mallon, cuya interpretación, como ya indiqué en crónica anterior, no resultaba convincente ${ }^{230}$.

Un estudio de los epígrafes de la Bética desde el punto de vista fonético ha publicado M. ${ }^{a}$ E. Martínez Ortega ${ }^{231}$.

\section{Tarraconense}

G. Alföldy ha dedicado una amplia reseña ${ }^{232}$ al libro de Tranoy sobre la Galicia romana ${ }^{233}$ : en ella pone de relieve la debilidad del argu-

${ }^{227}$ R. Atencia, Jábega 35, 1981, pp. 47-54; idem, La problemática de la epigrafia anticariense, Málaga 1981, y De epigrafia nescaniense, Baetica 5, 1982, pp. 115-119.

A $7 \mathrm{kms}$. de Antequera estaba Singilia Barba; sobre esta ciudad, vid. S. Ordóñez, Habis 18-19, 1987-88, pp. 319-344; sobre la existencia de un pagus singiliensis en un epigrafe del entorno de Astigi, vid. idem, Colonia Augusta Firma Astigi, Sevilla 1988, pp. 83-84; una monografia sobre Singilia Barba, que incluye 5 inscripciones inéditas, ha publicado R. Atencia: entre ellas, 2 de Herii - uno de ellos IIuir-- honrados por los ciues et incolae [mun.] liberi Singiliensis.

Otros estudios sobre epígrafes en la provincia de Málaga: L. Roldán et alii, Cuad. de Preh. ${ }^{a}$ y Arq. 9-10, 1982-83, pp. 221-223: funeraria inédita; P. Rodriguez Oliva, Mainake 4-5, 1982-83, pp. 243-250; P. Rodríguez Oliva y R. Atencia, BSAA 49, 1983, pp. 151-162: estelas de Sabora ( $A E$ 1983, nn. 524-528); R. Atencia, Mainake 6-7, 1984-85, pp. 177-186: CIL II 2015 reencontrado; idem, Baetica 10, 1987, pp. 139-151: 5 epigrafes inéditos de Cañete la Real, posible localización de Sabora. Varios trabajos de interés contiene el volumen Arqueología de Andalucia Oriental, Málaga 1981 .

${ }^{228} \mathrm{~J}$. Bonneville et alii, $M C V 20,1984$, p. 483 s. ( $A E$ 1984, nn. 530-531). M. Ferreiro, Gades 11, 1983, pp. 85-104, recoge las inscripciones de Asta Regia: todas conocidas.

${ }^{229}$ M. Mayer e I. Roda, Faventia 4, 1, 1982: 3 de la provincia de Sevilla; una de ellas presentada ya por los AA. al I Congr. And. de Est. Clás. (cf. crónica anterior: EMERITA 53, 2, 1985, p. 240, n. 178); G. Fabre, M. Mayer e I. Rodá, Ampurias 44, 1982, pp. 185-242, con 2 inéditas ( $A E$ 1983, nn. 620-621); M. Mayer, $A T H L O N$, in Hon. F. R. Adrados, Madrid 1987, pp. 603-611: nueva lectura de CIL II 6338 a, cf. Ampurias 44, 1982, n. 21: 2 fragmentos y 1 cristiana. p. 61.

230 J. Gil, Habis 16, 1985, pp. 183-186 ( $A E$ 1986, n. 325); cf. Fmerita 47, 1, 1979,

${ }^{231}$ M. ${ }^{a}$ E. Martínez Ortega, "El vocalismo de las inscripciones de la Bética", $G a$ des 8, 1981, pp. 197-220.

${ }^{232}$ G. Alföldy, "Zur Geschichte von Asturias et Gallaecia», Germania 61, 1983, pp. 510-538 ( $A E$ 1983, n. 543).

${ }^{233}$ A. Tranoy, La Galice Romaine, París 1981 ( $A E$ 1981, n. 523). Otra reseña: J. M. Alonso Núñez, Gnomon 55, 1983, pp. 663-664. 
mento ex silentio en el que se apoya la datación del comienzo de los conuentus iuridici en tiempo de Vespasiano ${ }^{234}$. El propio Tranoy, en colaboración con Le Roux, presenta un balance de las inscripciones romanas en la zona portuguesa al $\mathbf{N}$. del Duero ${ }^{235}$.

Sigue la polémica con respecto a la interpretación del signo $\supset: G$. Pereira acepta la interpretación de $\mathbf{M} .^{a} \mathbf{L}$. Albertos que lo refiere a un territorio - castellum -, no a una gentilidad ${ }^{236}$. Sostienen la opinión contraria Le Roux y Tranoy, que piensan que debe interpretarse como indicación de grupo de parentesco, con función similar a la que tiene domo, indicación que - como $\supset$ - desaparece a finales del s. $\mathrm{I}^{237}$; cabría oponer, sin embargo, que domo se refiere precisamente a un territorio: no precede a gentilicios, sino a topónimos.

Siguen siendo frecuentes en esta zona N. O. los hallazgos de dedicatorias a Júpiter Óptimo Máximo ${ }^{238}$; una de ellas es un altar de granito reutilizado, con dos textos: a) ex of. Elp(idi); b) $I O M^{239}$; se ha entendido que se trata del primer testimonio de officina en esta región; más bien parece que debería entenderse: ex of(ficio) Elp(idi): una dedicatoria a Júpiter por el favor hecho a Elpis ${ }^{240}$. También siguen apareciendo de-

${ }^{234}$ La nueva tabula de los Lougeii -..vid. supra apartado I.3, con n. 59 contradice el argumento. Vid. para esta cuestión M. ${ }^{a}$ D. Dopico, Gerión 4, p. 278, n. 16. Sobre la administración romana en el N.O. de la Península: N. Santos Yanguas, Brigantium 2, 1981, pp. 49-71.

${ }_{235}$ P. Le Roux y A. Tranoy, Conimbriga 23, 1984, pp. 19-41 ( $A E$ 1984, n. 538); iidem, Portugalia 4-5, 1983-84, pp. 199-207: se ocupan del problema de la escasez de ciudades en esta región $(A E 1984, \mathrm{n} .540)$.

${ }_{236}$ G. Pereira, Zephyrus 34-35, 1982, pp. 249-267 ( $A E$ 1983, n. 545); esta interpretación está ya presente en otros trabajos de este A., cf. crónica anterior: EMFRITA $53,2,1985$, p. 244, n. 202.

Sobre nuevos epigrafes con este signo, vid. supra n. 123.

${ }^{237}$ P. Le Roux y A. Tranoy, AEArq. 56, 1983, pp. 109-121; una sintesis de la cuestión ofrece J. M." Blázquez, Symbolae (Hom. Mitxelena) I, 1985, pp. 565-586 (AE 1986, n. 383).

${ }^{238}$ L. dos Santos, P. Le Roux y A. Tranoy, Bracaraugusta 83-84, 1983, pp. $182-$ 205 ( $A E$ 1983, nn. 549-580); las correspondientes a $A E$ 549-554 son dedicatorias a Júpiter; las demás corresponden a diferentes categorias de epigrafes; algunos (564$565)$ de contenido enigmático.

$239 A E 1983$, n. 551; A. Tranoy, Gallaecia 7-8, 1984, p. 270.

240 Sobre Helpis / Elpis, vid. IRMNa nn. 30-31 y p. 62, n. 41.

Otras dedicatorias a Júpiter: X. Rodríguez y A. Seara, Bol. Aur. 13, 1983, p. 23 ss., n. 2; C.A.F. de Almeida, Arqueologia (Porto) 5, 1982, pp. 69-70: puesta por los uicani Vagornicenses ( $A E$ 1982, n. 567); D. M. da Silva, Bracaraugusta 36, 1981, p. 244 ( $A E$ 1982, n. 566); C. Ervedosa, Trab. Antr. e Etnol. 25, 1, 1985, p. 167 ( $A E$ 1985, n. 574).

Nuevas lecturas: P. Le Roux y A. Tranoy, Minia 6, 1982, pp. 31-37: sobre CIL II 2388, con todo, la lectura es incierta $(A E$ 1983, n. 581); P. Le Roux, Épigraphie Hispanique (supra, n. 2), pp. 175-180: la dedicatoria de Corporales es una nueva copia de $C I L$ II 2552 ( $A E$ 1984, n. 556). 
dicatorias a los lares uiales ${ }^{241}$. Rodríguez Colmenero ha hecho un nuevo intento de lectura e interpretación del epigrafe rupestre $C I L$ II 2476 (cf. $A E$ 1981.527) ${ }^{242}$; a una dedicatoria imperial pertenece seguramente un nuevo fragmento procedente de la provincia de Orense ${ }^{243}$. En lo que respecta a inscripciones funerarias, se detecta la primera mención de la fórmula post mortem en esta zona ${ }^{244}$.

Bajo el titulo "Cantabria and the era consularis» publica Knapp un estudio que recoge las 18 inscripciones cántabras con esta datación, cuyo punto de partida es, según este A., la reorganización administrativa que siguió a la concesión del ius Latii hecha por Vespasiano ${ }^{245}$.

241 A. Garcia Linares, Bol. Inst. Est. Ast. 107, 1982, p. 773 ss. (AE 1984, n. 558); J. Delgado, Brigantium 4, 1983, pp. 209-214; S. Santamaria, Mem. H." Ant. V, 1983, pp. 125-130: revisión de $A E 1946$, n. 194; 1962, n. 397: propone leer La(res) pa(trii), cf. A. Tranoy, La Galice Romaine, p. 320.

Dedicatoria a otras divinidades: D. Pinho Brandão, Arqueologia 10, 1984, p. 15 (AE 1984, n. 543); C. A. Brochado de Almeida, Portugalia n.s. 2-3, 1981-82, pp. 167-171 ( $A E$ 1983, n. 587); de carácter dudoso: A. M. “ Canto y C. Fernández. Ochoa, BIEA 1985 , pp. 483-486 ( $A E$ 1985, n. 578).

Revisiones: J. C. Admonson, Conimbriga 23, 1984, p. 72 ss.: Sobre HAEpigr. 2695 ( $A E$ 1984, n. 465); $A E$ 1985, nn. 529-531: sobre las aras de la provincia de Orense publicadas por M. Cavada, Actas I Reunión Gallega de Est. Clás., Santiago de Compostela 1981, pp. 151-158. Sobre balnearios y dioses de las aguas termales en la Galicia romana: F. de P. Díez de Velasco, AEArq. 58, 1985, pp. 69-98.

242 A. Rodriguez Colmenero, Arqueologia 12, 1985, p. 195 ss. ( $A E$ 1985, n. 577). Sobre anteriores intentos, vid. EMERITA 53, 2, 1985, pp. 244, n. 205.

A. Coelho y F. da Silva, Portugalia n.s. 2-3, 1981-82, p. 89: revisión del epigrafe grabado sobre el escudo de una estatua de guerrero indigena ( $A E 1981, \mathrm{n} .526$, cf. $A E$ 1983, n. 548); otra, grabada en estatua de guerrero: M. Martins y A. Coelho da Silva, Cad. de Arq. 1, 1984, p. 36 (AE 1985, n. 573).

L. dos Santos, P. Le Roux y A. Tranoy, Bracaraugusta 37, 1983, p. 201: sobre una estela de granito sin decoración, la leyenda Seueri, que quizá indicará un límite de propiedad ( $A E$ 1983, n. 578).

243 X. Rodríguez González y A. Seara, Bol. Aur. 13, 1983, p. 29: ...uliae Aug.

244 C. Ervedosa, Trab. Antr. e Etnol. 24, 2, 1982, p. 353 ( $A E$ 1982, n. 568, con mejora de lectura, y $A E$ 1983, n. 585).

Otras funerarias nuevas: B. Afonso, Brigantium 1, 1981, pp. 148-150 (AE 1982 , nn. 572-573); B. Alfonso y J. M. Morais, ibid. p. 82 ( $A E$ 1982, n. 574); P. Le Roux y A. Tranoy, Minia 6, 1982, p. 33 ss. ( $A E$ 1983, nn. 582-583); C. A. Brochado de Almeida y M. Alves Placido, Arqueologia 7, 1983, pp. 48-52 ( $A E$ 1983, n. 584, de lectura poco segura); F. Acuña y R. Casal, Brigantium 2, 1981, p. 271 ( $A E$ 1983, nn. 589-590, lectura insegura); J. M. Caamaño, Not. Arq. Hisp. 18, 1984, p. 228; A. Rodríguez. Colmenero y M. C. Carreño, Hom. Pinho Brandão, pp. 213-237 (AE 1984. nn. 544-546); F. Patricio Curado, $F E$ 14, 1985, n. 63 ( $A E$ 1985, n. 575); A. J. Nunes Monteiro, ihid. 10, 1984, n. 42 ( $A E$ 1985, n. 576).

Relecturas: A. Balil, Bol. Mus. Prov. Lugo 1, 1983, pp. 179-183: sobre IRG I, n. 17; J. C. Rivas, Bol. Aur. 13, 1983, pp. 75-98: sobre $I R G$ IV, n. I: señala que no es un ara votiva, sino una estela funeraria bifronte; la lectura que da es insostenible, pero quizá tenga razón respecto a que se trate de una funeraria.

${ }_{245}$ R. C. Knapp, Epigraphica 48, 1986, pp. 115-116.

Otras inscripciones de la zona cántabra: M. García Alonso, Altamira 44, 1983- 
Ha aparecido un estudio de conjunto de las estelas vadinienses ${ }^{246}$. Abásolo publica una serie de 33 piezas correspondientes a la provincia de Burgos ${ }^{247}$. García Merino se ocupa de varias piezas procedentes de la provincia de Soria ${ }^{248}$. F. Beltrán ofrece un resumen de la epigrafia de

84, p. 115, mal leída; J. González Echegaray y J. L. Casado, Altamira 45, 1985, pp. 305-312: fragmento de funeraria reutilizado; J. M. Iglesias Gil, $F E$ 19, 1986, n. 86: dedicatoria a Júpiter en Iuliohriga ( $A E$ 1986, n. 400$)$; idem, ibid., n. 89 ( $A E$ 1986, n. 401): funeraria incompleta.

En la región vasca: J. Gorrochategui y M. J. Yarrito, Cuad. Arq. de Deusto 9. 1984, pp. 128-145: catálogo de las inscripciones de Vizcaya; ninguna inédita, pero pocas de CIL ( $A E$ 1984, n. 581). E. García Retes et alii, Est. Arq. Alavesa 12, 1983, pp. 343-363: inscripciones de la provincia de Álava ( $A E$ 1986, nn. 403-410). Idem, ibid., pp. 285-342.: inscripciones de Ocáriz ( $A E$ 1986, nn. 411-422). Sobre esta provincia puede verse M." C. González, "Síntesis histórica de epigrafia romanoalavesa", Veleia 1, 1984, pp. 217-232.

2 th Cf. supra, n. 29.

En la provincia de León: J. Mangas y J. Vidal, Mem. H. ${ }^{a}$ Ant. 8, 1987, pp. 191198: 5 ineditas; J. Mangas, Symbolac (Hom. Mit.celena) I, pp. 587-591: una inscripción griega de Astorga ( $A E$ 1986, n. 388); M." L. Albertos, $B S A A$ 50, 1984, pp. $216-$ 220: funeraria.

Revisiones: G. Alföldy, Gerión 3, 1985, p. 390 ( $A E$ 1985, n. 579): sobre $A E 1987$. n. 237; J. Mangas, Hisp. Ant. 11-12, 1981-1985, pp. 119-125: sobre Cat. Mus. León. p. 3; T. Mañanes, Hisp. Ant. 9-10, 1979-1980 (publ. 1983), pp. 191-195 (AE 1984, n. 554): sobre $A E$ 1983, nn. 591-592.

En la provincia de Zamora: A. Pedregal, Mem. H." Ant. 8, 1987, pp. 187-190: funeraria inédita.

En la provincia de Salamanca: R. Martin Valls y M. J. Frades, Numantia 2 , 1982, pp. 195-198: sobre un verraco.

En la provincia de Valladolid: M. García Alonso, BSSA 51, 1985, pp. 258-260 ( $A E$ 1986, n. 391): ara a Júpiter; J. Mangas, Mem. H. "Ant. 4, 1980 (1982), p. 220: foto de funeraria sin lectura.

En la provincia de Palencia: M. C. Lion, BSAA 53, 1987, pp. 206-210: dos funerarias.

247 J. A. Abásolo, BSAA 50, 1984, pp. 195-216 ( $A E$ 1984, nn. 560)-579: algunas de dificil lectura); la n. 9 tiene carácter monumental y da lugar a la hipótesis de un centro urbano; la n. 10 corresponde a un personaje de rango ecuestre, cf. supra, $\mathrm{n}$. 95; Idem, $A E A r q .58,1985$, pp. $159-174$ ( $A E$ 1985, nn. 582-594): 19 textos, en buena parte fragmentarios, correspondientes a diversas provincias; entre ellos, un epigrafe rupestre dedicado a Hércules; idem, Sautuola 3, 1982, p. 134 ( $A E$ 1984, n. 580): funeraria inédita.

Proceden también de esta provincia: M." L. Albertos y J. A. Abásolo, Publ. Inst. Téllez 37, 1976, pp. 259-265: 3 lápidas burgalesas conservadas en una colección privada de Palencia; J. Mangas e I. Cortina, Mem. H. ${ }^{\prime A n t . ~ 5, ~} 1982$ (1983), pp. 269-271 $(A E 1983$, n. 600$)$ : funeraria con texto doble; en lin. 2, en vez de $[A] R C E A E$ debe leerse seguramente $[M A] R C I A E$; la procedencia es incierta. G. Fabre, M. Mayer e I. Rodá, Ampurias 44, 1982, pp. 185-242: en la última lín. de la n. 14, ATISVENATONI interpretado como nombre de gentilidad; parece más seguro que se trate del nombre de una divinidad en Dativo.

${ }_{248}$ C. García Merino, "Addenda a la epigrafia de Uxama y la nueva estela de S. Esteban de Gormaz", Hom. Almagro III, Madrid 1983, pp. 335-364 ( $A E$ 1983, nn. 595-599). Ofrece revisión de Jimeno, ERPSoria n. 86 ( $A E$ 1980, n. 563); eadem, $N u$ mantia 2, 1986, p. 280 ss.: inscripciones del Burgo de Osma ( $A E$ 1986, nn. 396-399). 
la provincia de Huesca ${ }^{249}$, en la que destacan: un glans de plomo con la leyenda $Q$. Sertorius procos. ${ }^{250}$; una inscripción que se creía redactada en "vasco ribagorzano» y que resulta ser latina; una tabula de bronce con la inscripción uenalis non est ${ }^{251}$; una musiva (ILER 2107) que contiene un verso de Virgilio, y un conjunto cristiano fechable en el s. IV ${ }^{252}$. En Navarra se ha encontrado una placa de bronce con la inscripción: Apollini / Aug. / Sempronius Ca/rus Siluini f. / Lucretius Marti/alis Lucreti f. / aediles / d.s.p.f.c. ${ }^{253}$

Por lo que respecta a Castilla la Nueva, contamos ahora con una monografia de Alföldy en la que menciona los epígrafes relacionados con las ciudades y su administración ${ }^{254}$. Una inscripción monumental de Titulcia (prov. Madrid) da a conocer a una familia notable de la ciudad, inscrita en la Quirina ${ }^{255}$. Entre las piezas conservadas en el Museo de Santa Cruz de Toledo se encuentra un fragmento que debe de corresponder a los juegos circenses pagados por un seuir ${ }^{256}$; Alföldy ha

En la misma provincia: M. J. Borobio, J. Gómez Pantoja y F. Morales, Celtiberia 74,1987, pp. 239-258: 13 epigrafes inéditos y relación de inscripciones revisadas o publicadas después de 1980; J. Mangas y M. J. Ramírez, Mem. H. ${ }^{a}$ Ant. 4, 1980 (1982), p. 221 ss.: funeraria inédita; A. Balil, «'Magius M.f. Gal. Antiquus' en una inscripción de S. Esteban de Gormaz», Numantia 2, 1982, pp. 199-201; G. Fabre, M. Mayer e I. Rodá, Ampurias 44, 1982, n. 34: sobre CIL II 5794.

En la provincia de Segovia: M. ${ }^{a}$ L. Albertos, Numantia 2, 1982, pp. 203-206: inédita de Coca; J. Santos Yanguas, Symbolae (Hom. Mitxelena), Vitoria 1985, p. 539: revisión de CIL II 5095 ( $A E$ 1986, n. 391); L. A. Curchin, ZPE 58, 1985, p. 245, n. 5 ( $A E$ 1985, n. 595): revisión de $A E 1980$, n. 585 d.

${ }^{249}$ F. Beltrán, Annales 4, 1987, pp. 19-35.

${ }^{250}$ Publicado en 1984, vid. supra, n. 37.

251 Cf. supra, n. 63.

${ }^{252}$ Cf. supra, n. 176.

Otras inscripciones aragonesas: J. L. Jiménez y J. Liz, Hom. Cabré Aguiló, Zaragoza 1984, p. 217 ss., retomado por M. Medrano y M. A. Díez, Kalathos 50, 198586, p. 171 ss., que interpretan C. Alliar(ius) d(onauit); I. J. Bona, $F E 8$, 1984, n. 33 $(A E 1984$, n. 582): funeraria de Tarazona; C. Barriendo, $F E$ 18, 1986, n. 80: fragmentaria de Tarazona; F. Marco Simón, Kalathos 2, 1982, p. 41 (AE 1982, n. 592): lectura dudosa.

${ }^{253}$ M." A. Mezquíriz, Trab. Arq. Navarra 4, 1984, p. 185 s.; en la misma provincia: F. Marco Simón, Trab. Arq. Navarra 1, 1979, pp. 233-244: 5 estelas decoradas presentadas como inéditas, con lectura muy insegura ( $A E$ 1982, nn. 582-586).

En La Rioja: U. Espinosa, $Z P E$ 51, 1983, pp. 199-203 (AE 1983, n. 601): $B R A H$ 50,1907 , p. 293, dada por perdida; el texto reproducido por Fita tenía sólo 5 líneas; el original tiene 8, con la fórmula final in memoriam sibi et suis, que resulta un tanto extraña en un epigrafe dedicado Fortunae Augusti (Fita: Fortunae Augustae); en otros similares (CIL II suppl. p. 1202), sigue a memoriam un Genitivo. Idem, ZPE 58, 1987, pp. 241-246: relectura de CIL II 2892.

234 Vid. supra, n. 68.

${ }^{255}$ S. Mariner, Hom. Almagro III, Madrid 1983, p. 347 ss. (AE 1983, n. 603).

${ }^{256}$ S. Cortés et alii, Museos 3, 1984, pp. 75-76, n. 6, donde seguramente debe leerse: [ob hon]or(em) IIIIIIuir(atus) / [ludis] circensibus editis; S. Cortés et alii, Car- 
reunido los epígrafes de personajes no ingenuos de Toledo y sus cercanías: son un total de $15^{257}$; en esta misma provincia, ha aparecido un mosaico tardío que contiene la fórmula utere felix ${ }^{258}$. El conjunto de las inscripciones de Segobriga (prov. Ciudad Real) publicado por Almagro contiene algunas conservadas en el Museo Arqueológico Nacional que no publicaron Fita ni Hübner, y un número relativamente amplio de inéditas ${ }^{259}$; las correspondientes al templo de Diana han sido posteriormente estudiadas por Alföldy ${ }^{260}$; en esta misma provincia se ha hallado una dedicatoria a Trajano ${ }^{261}$.

En el volumen titulado Castulo $I V$ se contiene una sintesis de las inscripciones de esta ciudad, concebida como continuación de la publicada en Castulo II, que se dedicaba a prosopografia ${ }^{262}$. Una dedicatoria de Aurgi honra a un duouir del municipio flavio Aurgitano, que debía de ser ciudadano de antiguo cuño, porque está adscrito a la Galeria ${ }^{263}$; en Galera (prov. Granada) se ha encontrado una dedicatoria de la res-

petania 1, 1987, pp. 91-102: 8 inéditas o poco conocidas, entre ellas 2 aras a IOM y la funeraria de un signifer.

${ }_{257}$ G. Alföldy, ZPE 67, 1987, pp. 249-262; idem, Studi tardorromani 2, 1986, p. 177 ss.: placa con doble inscripción, funeraria en el anverso, y en el reverso visigótica, vid. supra, n. 177.

${ }_{258}$ J. Arce, MM 27, 1986, pp. 365-374: Ex oficina. Ma...ni/pingit Hirinius / utere felix, Materne, / hunc cubiculum; obsérvese algunos rasgos de lengua vulgar: simplificación de geminadas $-f f-,-n n-$ y vacilación de timbre $e / i$ : Hirinius por Herennius, utor con régimen en Acusativo; el A. fecha en s. III/Iv d. C.

${ }_{259}$ M. Almagro Basch, Segobriga II, Madrid 1984, cf. supra, nn. 27 y 113; los nn. 135 al 264 son pequeños fragmentos, inéditos desde el 176 (salvo el n. 181); con anterioridad, idem, Hom. Sáenz de Buruaga, 1982, pp. 339-350: 3 votivas a Hércules.

260 G. Alföldy, $Z P E$ 5, 1985, pp. 139-159 ( $A E 1985,616-620)$; idem, ibid., 67. 1987, pp. 225-248: 19 tituli, de los cuales 18 son inéditos: entre ellos, unos disticos elegíacos reconstruidos.

${ }_{261}$ C. Pérez Pérez, Cuad. de Preh. ${ }^{a}$ y Arq. 7-8, 1980-81, pp. 173-174: fragmentaria, faltan los datos que permitirian fecharla.

Otras inscripciones de Ciudad Real: L. de Cañigral y C. Carrasco, Cuad. de Filologia 5, 1985, pp. 115-119: funeraria inédita; C. Fernández Ochoa el alii, Oretum 2, 1986, pp. 310-315 y 317-319: funerarias; C. Fernández Ochoa y A. Caballero, Cuad. de Preh. “ y Arq. 7-8, 1980-81, pp. 169-172: ara muy rústica a IOM.

En $A E$ 1982, nn. 600-620 se recogen, con correcciones, las novedades que Rodriguez Colmenero presentaba en su catálogo de la provincia de Cuenca (cf. crónica anterior: EMERITA 1985, p. 209, n. 13, donde ya se hacia notar que precisaba una revisión), vid. supra, n. 27. Nótese que la n. $75(A E 1982, \mathrm{n} .607)$ no es un miliario sino una dedicatoria honorifica a Diocleciano.

262 J. M. Blázquez et alii, Castulo IV (Exc. Arq. n. 131), Madrid, 1984. Anexo I: Miscelánea Castulonense II; Vid. también: M. Pastor, Zephyrus 37-38, 1984-85, pp. 341-348.

${ }_{263}$ C. González Román y M. A. Marin, Cuad. Preh." Univ. Granada 10, 1985, pp. 449-460: 3 epigrafes inéditos; nos referimos al $n$. 1 , fechado en los últimos años de los flavios o el comienzo de los Antoninos. Para la tribu Galeria, puede verse C. Castillo, Est. sobre la tabula Siarensis, Madrid 1988, pp. 233-241. 
publica Tutugiensis a Heliogábalo y otra puesta a Caracala por un duouir de la ciudad ${ }^{264}$.

Especial interés reviste el hallazgo de numerosos tituli picti en la llamada Cueva Negra de Fortuna (prov. Murcia): al estudio de este material se dedica un volumen misceláneo; la lectura y comentario de los textos corre a cargo de A. U. Stylow y M. Mayer, quienes concluyen que se trata de un santuario a las ninfas, aunque los textos no son culturales sino de carácter literario, métricos en su mayor parte, modelados sobre Virgilio y Ovidio ${ }^{265}$. M. Koch ha publicado cinco nuevos epigrafes de Carthago Noua ${ }^{266}$.

Una inscripción encontrada en Liria menciona un bellum Mauricum $^{267}$, lo que ha dado pie a Alföldy para volver sobre la cuestión de la invasión de los Mauri en la Bética en tiempo de Marco Aurelio ${ }^{268}$.

${ }^{264}$ En la zona norte de la provincia de Granada: M. R. de Cárdenas, Cuad. Preh." Univ. Granada 10, 1985, pp. 463-468: en la primera lín. conservada seguramente debe leerse $P$ u(blilia tribu); J. González, Mainake 2, 1980, pp. 130-145 (AE 1985, nn. 608-610): incluye una rectificación sobre la procedencia de CIL II 3003-3005, atribuidos por Hübner a $O s c a$, cuando realmente proceden de Huéscar (provincia Granada); idéntica observación hace A. Alvar (J. Alvar por error), Hisp. Ant. 9-10. 1979-1980 (1983), pp. 231-247 ( $A E 1984$, n. 598).

265 La Cueva de Fortuna y sus 'tituli picti', Murcia 1987, ed. A. González Blanco, M. Mayer y A. U. Stylow. La primera noticia del hallazgo (1980), se presentó en el coloquio celebrado en Oviedo en 1981, cf. A. González Blanco et alii, Mem. H." Ant. 3, 1979, pp. 277-284.

Otras inscripciones de Murcia: I. Garcia Jiménez, An. de Preh.“ y' Arq. 2, 1986, pp. 131-135: tres inéditas y una redescubierta; una de ellas procede de Cartagena, vid. infra, n. 266; la n. I dice: Cn. Numisius Cn. I. / Epigonus / heic sepultus est / aue. salue; fechada por la A. a mediados del s. I d.C., aunque más bien parece, por su formulario, de época republicana.

En la provincia de Albacete: L. Roldán, Al-basit 20, 1987, pp. 37-66: con una funeraria de Almansa que creo debe leerse C'ania / Maxsuma / Ti.f.h.s.est. J. F. Martín, Zephyrus 37-38, 1984-85, pp. 337-340.

2to M. Koch, $M M$ 28, 1987, pp. 127-134: entre ellas una funeraria con el nombre del difunto en Vocativo, seguido del saludo salue; otra cf. supra, n. 265 corresponde a un liberto de los Numisii, familia importante de la ciudad, y debe fecharse como muy tarde a comienzos del Imperio, como también la funeraria de Turpilius Statius Maior, probablemente de origen itálico. Un resumen de las grandes familias de Carthago Noua ofrece el propio Koch en Actas CPHA (supra, n. 22), pp. 403-408.

267 J. Corell, AEAry. 149-150, 1984, pp. $177-178$ (AE 1985, n. 622), donde se menciona ya el artículo de Alföldy que recojo en la nota que sigue.

$26 \times$ G. Alföldy, Chiron, 15, 1985, pp. 91-109; vid. supra, apartado 1.9 y n. 100; sobre otros epigrafes de la región valenciana: idem, $Z P E$ 53, 1983, pp. 103-111: relectura de CIL II 3605=5972; idem, ZPE 54, 1984, pp. 222-245 ( $A E$ 1984, nn. 599604): inscripciones de Jérica y alrededores; en la n. 601, un dedicante con tribu $G a-$ leria.

Otras inscripciones del país valenciano: L. Abad Casal, Lucentum 3, 1984. pp. 193-200; J. Corell, $A P L$ 19, 1987, pp. 271-281; un total de 7, con 2 inéditas; idem, Afers 2, 1985, pp. 203-225: 6 inéditas y 2 ya conocidas de Sagunto; idem. Saguntum 19. 1985, pp. 279-299: 11 inéditas y una relectura; en la n. 6, un Didius adscrito a 
Las piezas inéditas contenidas en el vol. I del corpus de inscripciones de Cataluña $(I R C)$ están recogidas en el tomo de $A E$ correspondiente a $1984^{269}$.

Hay un nuevo testimonio de culto mitraico en Iluro $^{270}$, y una nueva dedicatoria a Venus en Tarragona ${ }^{271}$. Sobre una inscripción de Ampurias, en la que se menciona el campus del municipio, ha vuelto a tratar M. ${ }^{a}$ J. Pena ${ }^{272}$. A. Balil se ha ocupado de las tesserae lusoriae de esta misma ciudad ${ }^{273}$.

Carmen Castillo

la Galeria; en la n. 9 no creo que deba leerse $T[r o] /($ mentina $)$, tribu rara y además onomástica femenina; más probablemente: $T$. / n(epos); idem, Arse 21, 1986, pp. 5556: sobre CIL II 3871; idem, Arse 20, 1985, p. 28: 2 a Liber pater (las mismas que publica F. Roca en Arse 18, p. 13 ss., pero mejor leidas) ( $A E$ 1986, n. 457); F. Roca, Arse 18, 1983, pp. 13-16: un total de 3, que incluye las dos mencionadas a Liber pater; idem. Arse 19, 1984, pp. 56-57: 8 fragmentos, 3 de ellos métricos; idem, Arse 20, 1985, p. 532 ( $A E 1986$, n. 458); idem, Arse 21, 1986, pp. 67-72: varios fragmentos; 3 de ellos parecen componer un epitafio versificado; otro es ibérico; M. Cortina, Arse 17, 1982, pp. 79-80: funeraria mal leida; las letras finales deben interpretarse como förmula: $u$ (iuus) f(ecit) $s($ ibi) $e(t) s($ uis); C. Aranegui et alii, AEArq. 59, 1986, pp. 47-66: relectura de CIL II 3821 y 3822, cf. J. N. Bonneville, Saguntum 19, 1985, pp. $255-273$ ( $A E 1985$, n. 623$)$; F. Escriche publica una votiva a la Fortuna en el diario Las Provincias 25-I-86.

En Alicante: L. Abad y M. Bendala, Lucentum 4, 1985, pp. 147-184. En Castellón: F. Arasa Gil y J. Vicent, Cuad. de Preh." y. Arq. Castellonense 9, 1982-83, pp. 249-250: 3 funerarias incompletas ( $A E$ 1986, nn. 445-447). Diversas relecturas de textos procedentes de la provincia de Castellón y de las Islas Baleares: G. Fabre, M. Mayer e I. Rodá, Ampurias 44, 1982, pp. 185-242.

264 G. Fabre, M. Mayer e I. Rodá, IRC I. Barcelone sauf Barcino ( $A E$ 1984, nn. 607-612); para otros trabajos integrados en este corpus, vid. supra, n. 23. En la correspondiente a $A E 1983$, n. 628 se propone nueva lectura de un epigrafe publicado por Mariner (vid. HMERITA 53,2, 1985, p. 247, n. 220): aliarius no sería cognomen ni significaría 'jugador de dados', sino 'comerciante de ajos'. Otros trabajos de epigrafia catalana supra, n. 7, y además M. Mayer e I. Rodá, Fonaments 5, 1984, pp. 161186 ( $A E$ 1985, nn. 625-634).

Nuevas lecturas: L. A. Curchin, $B S A A$ 51, 1985, pp. 256-257 ( $A E$ 1986, n. 384); J. J. Segui, St. Hist. 2-3, 1984-85, pp. 129-139: sobre (II. II 4465.

270 J. Bonanusa i Roure, Laielania 2-3, 1982-83, pp. 248-253. Sobre el culto de Mitra, vid. supra, n. 12.

271 F. J. Montón. Not. Arq. Hisp. 21, 1985, p. 353 (AE 1986, n. 461). También se refiere a cultos en Tarragona J. M. Serrano, "Sevir Augustalis Magister Larum Augustalium en Tarraco", Actas ( PHA (supra, n. 22), pp. 23-26.

272 M." J. Pena, Est. de la Ant. 3, 1986, pp. 149-154: la inscripción que publicó la A. en Quaderns de Trehall 4, 1981, es de época augustea, anterior al cambio de era; respecto a campus: Devijver y van Wonterghen han interpretado mal lo anteriormente dicho por la $\mathrm{A}$.

273 A. Balil, $A P I, 17,1987$, pp. 331-336.

Otros epigrafes de la provincia de Gerona: M." del V. Vila, Pyrenae 17-18, 198182, pp. 329-334: pedestal en el que se honra a un edil y IItuir de Aeso inscrito en la Quirina; R. F. Jones ('t alii, Antiquaries Journal 62, 1982, p. 273: una dedicatoria a Druso, hijo de Germánico ( $A E$ 1983, n. 6.31).

Nuevas lecturas: J. N. Bonneville, Empories 45-46, $1983-84$ (1987), pp. 324-329: sobre CII. II 6189. 